\title{
A novel ETV6-miR-429-CRKL regulatory circuitry contributes to aggressiveness of hepatocellular carcinoma
}

Chunmei Guo ${ }^{1 \dagger}$, Chao Gao ${ }^{1 \dagger}$, Dongting Zhao ${ }^{1 \dagger}$, Jiahui Li², Jinxia Wang ${ }^{1}$, Xujuan Sun', Qinlong Liu ${ }^{3}$ Lihong Hao ${ }^{4}$,

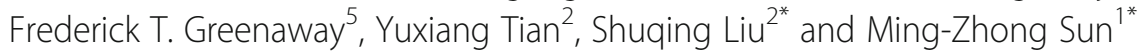

\begin{abstract}
Background: Tumor metastasis is one of the main causes of the high mortality of hepatocellular carcinoma (HCC). E-Twenty Six variant gene 6 (ETV6) is a strong transcriptional repressor, associated with the development and progression of tumors. However, the exact role and underlying mechanism of ETV6 in HCC remain unclear.

Methods: Western blotting, quantitative real-time PCR and immunohistochemistry were used to detect the expression levels of ETV6, CRKL ( $v$-crk sarcoma virus CT10 oncogene homologue (avian)-like) and miR-429 in HCC tissues and cells; Transwell chamber and F-actin cytoskeleton staining assay to examine the effects of ETV6 and CRKL deregulation on the migration, invasion and cytoskeleton of HCC cells; Co-immunoprecipitation assay to determine the interaction between CRKL and ETV6; Chromatin immunoprecipitation assay to investigate the interaction between ETV6 and miR-429.
\end{abstract}

Results: We established a novel ETV6-miR-429-CRKL regulatory circuitry contributes to HCC metastasis. ETV6 and CRKL were frequently increased, while miR-429 was downregulated in both hepatocarcinoma tissues and hepatocarcinoma cells. Moreover, ETV6 upregulation was positively correlated with CRKL upregulation, and two negative correlations were also established for ETV6 and CRKL upregulation with miR-429 downregulation in both hepatocarcinoma patients' tumorous tissues and hepatocarcinoma cells. Functional investigations revealed that overexpression and knockdown of ETV6 was remarkably effective in promoting and suppressing HCC cell migration, invasion, cytoskeleton F-actin expression and arrangement, whereas, CRKL overexpression exhibited similar effects to the overexpression of ETV6. Mechanistically, ETV6 negatively regulates miR-429 expression by directly binding to the promoter region of miR429; miR-429 negatively regulates CRKL expression by selectively targeting CRKL-3'-UTR; ETV6 directly binds to CRKL and positively regulates its expression, which in turn CRKL positively regulates ETV6 expression.

(Continued on next page)

*Correspondence: Isqsmz@163.com; smzlsq@163.com

${ }^{\dagger}$ Chunmei Guo, Chao Gao and Dongting Zhao contributed equally to this work.

${ }^{2}$ Department of Biochemistry, College of Basic Medical Sciences, Dalian Medical University, Dalian 116044, China

${ }^{1}$ Department of Biotechnology, College of Basic Medical Sciences, Dalian Medical University, Dalian 116044, China

Full list of author information is available at the end of the article

(c) The Author(s). 2020, corrected publication [2021] Open Access This article is licensed under a Creative Commons Attribution 4.0 International License, which permits use, sharing, adaptation, distribution and reproduction in any medium or format, as long as you give appropriate credit to the original author(s) and the source, provide a link to the Creative Commons licence, and indicate if changes were made. The images or other third party material in this article are included in the article's Creative Commons licence, unless indicated otherwise in a credit line to the material. If material is not included in the article's Creative Commons licence and your intended use is not permitted by statutory regulation or exceeds the permitted use, you will need to obtain permission directly from the copyright holder. To view a copy of this licence, visit http://creativecommons.org/licenses/by/4.0/. The Creative Commons Public Domain Dedication waiver (http:// creativecommons.org/publicdomain/zero/1. 0/) applies to the data made available in this article, unless otherwise stated in a credit line to the data. 


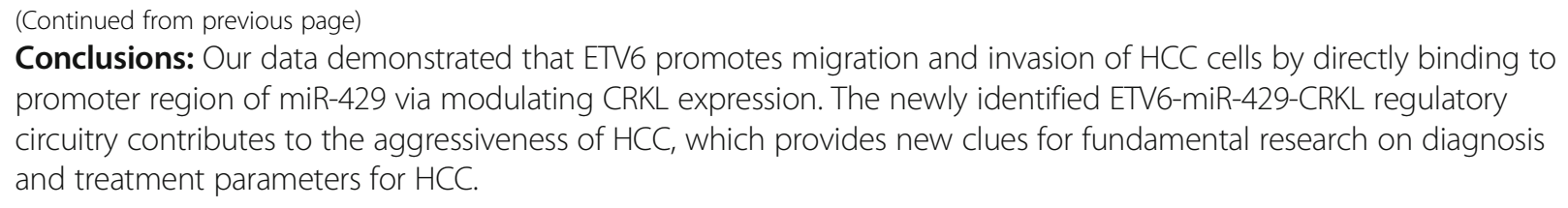

\section{Background}

Hepatocellular carcinoma $(\mathrm{HCC})$ is one of the most common cancers worldwide. Its morbidity and mortality rate are among the highest in the world $[1,2]$. Tumor metastasis is the major problem leading to its high recurrence with low post-surgical 5-years survival and high mortality [3-5]. It is a multistep process, including the invasion of extracellular matrix (ECM), intravasation, translocation, migration and invasion of a secondary site, and finally the formation of metastatic nodules [3-5]. Deeper study of the molecular mechanisms of HCC metastasis can lead to novel therapeutic targets and improve the prognosis for $\mathrm{HCC}$ patients.

E-Twenty Six (ETS) variant gene 6 (ETV6), also known as translocation ets leukaemia (Tel), is a member of the transcription factor ETS family [6]. It is composed of a helix-loop-helix (HLH) domain [also named as pointed domain (PNT), or sterile alpha motif domain (SAM)] at the N-terminus and an ETS domain at the Cterminus. The HLH domain is necessary for homodimerization and heterodimerization with other ETS family members, it also frequently contributes to fusion proteins as the partner of tyrosine kinases [7, 8]. The ETS domain is responsible for sequence specific DNAbinding to the ETS-binding consensus site (EBS) [6-8]. ETV6 is known to form fusion proteins by chromosomal translocations with the platelet-derived growth factor receptor (PDGFR), v-abl Abelson murine leukemia viral oncogene $(\mathrm{ABL})$, runt-related transcription factor 1 gene (RUXN1), ecotropic virus integration site-1 (EVI-1) through the HLH domain, leading to the homodimerization of fusion proteins and to constitutive activation of tyrosine kinase activity [9]. The HLH domain of ETV6 could mediate dimerization of $\mathrm{ABL}$ and subsequent $\mathrm{ABL}$ kinase domain activation [10]. CRKL (v-crk sarcoma virus CT10 oncogene homologue (avian)-like) is a substrate protein for ABL, Tel-ABL fusion protein can form complexes with CRKL leading to tyrosine-phosphorylation of CRKL and the constitutive activation of Ras (rat sarcoma), MAPK/ERK (mitogen-activated protein kinase/extracellular regulated protein kinases) and PKB/AKT (protein kinase $\mathrm{B} /$ Serine/threonine kinase) [10]. ETV6 also acts as a strong transcriptional repressor by directly binding to target genes through the ETS DNA-binding domain to repress its transcription [11, 12]. ETV6 plays a crucial role in embryonic development and hematopoiesis [13]. Its deregulation is also involved in the development and progression of leukemia, prostate cancer, colorectal cancer and non-small cell lung cancer [14-18]. However, the biological function and underlying regulation mechanism of ETV6 in HCC remain unclear.

CRKL, a member of the CRK adapter protein family, is ubiquitously expressed and conserved across eukaryotic organisms [19]. It is composed of one NH2-terminal Src homology2 (SH2) domain, one N-terminal SH3 (SH3N) domain and one C-terminal SH3 (SH3C) domain. CRKL has a variety of linkages for coupling to proline-rich proteins BCAR1 (breast cancer anti-estrogen resistance 1), GAB (Grb2-associated binder protein), ABL, Pax (paired boxed gene), GEF (guanine nucleotide exchange factor), C3G (3-domain-binding guanine nucleotide exchange factor), BCR (B-cell receptor)-ABL and SOS (son of sevenless) to form timely and localized complexes that are critical for cell proliferation, survival, adhesion and migration [20, 21]. Hence it can function in cellular signaling cascades by either directly forms complex with downstream receptor protein to regulate cellular tyrosine kinase activity, or by acting as an upstream mediator for signal initiation [22, 23]. CRKL deregulation has been linked to the development and progression of a variety of cancers [24, 25]. We previously reported that the overexpression and knockdown of CRKL was remarkably effective in promoting and suppressing the in vitro migration and invasion capacities of hepatocarcinoma HepG2 cells [26].

MicroRNAs (miRNAs) are 18-24 nucleotide small non-coding RNAs that negatively regulate gene expression by directly degrading mRNA or by suppressing post-transcriptional protein translation by binding to the 3 '-untranslated region (3'-UTR) of targeted mRNAs [27]. MiRNAs play important roles in cell proliferation, differentiation, metastasis and apoptosis by directly degrading mRNA or by suppressing post-transcriptional protein translation by targeting mRNAs [28, 29]. MiRNAs might function as tumor promoter or suppressor in tumorigenesis and tumor malignancy [30]. miR-429, a member of miR-200 family, is located on chromosome 1 p36 [31]. miR-429 dysregulation is involved in the development, invasion, epithelial-mesenchymal transition (EMT), metastasis and drug resistance of various cancers 
$[32,33]$. It functions either as a tumor suppressor or tumor promoter for certain cancers depending on the particular type of tumor cell/tissue [34-36]. Our previous study showed that miR-429 negatively regulated CRKL expression by selectively binding to CRKL-3'UTR at the $3728-3735$ bp site by post-transcriptionally mediating CRKL's functionality, and miR-429 suppressed the migration and invasion of HepG2 cells by targeting CRKL via inhibiting Raf/MEK/ERK (rapidly accelerated fibrosarcoma/ mitogen-activated extracellular signalregulated kinase/ERK) pathway and EMT [26]. Bioinformatics analysis software JASPAR predicted that ETV6 protein potentially binds to the DNA promoter region at the 696-705 site of miR-429. We speculate that ETV6, CRKL and miR-429 may form an ETV6-miR-429-CRKL regulatory loop.

In the present study, we report a new ETV6-miR-429CRKL regulatory circuitry in HCC. We found that ETV6 and CRKL were upregulated, and miR-429 was downregulated in HCC patients' tissues and HCC cell lines compared with corresponding non-tumor liver tissues and a normal liver cell line. Moreover, ETV6 knockdown inhibited the in vitro migration, invasion and F-actin cytoskeleton expression and arrangement of HCC cells, while ETV6 or CRKL overexpression showed opposite effects. We observed that overexpression of ETV6 caused repression of miR-429 and the inhibition of miR-429 lead to the upregulation of CRKL, which in turn CRKL overexpression promoted ETV6 expression. Meanwhile, the expression of ETV6 displayed a positive correlation with CRKL but an inverse correlation with miR-429. Furthermore, ETV6 directly binds to the promoter region at the 696-705 bp site of miR-429 by transcriptionally negatively mediating its expression; CRKL is a direct target of miR429 and miR-429 negatively regulates CRKL expression by selectively binding to $C R K L-3^{\prime}$-UTR at the $3728-3735$ bp site by post-transcriptionally mediating its functionality; ETV6 positively regulates CRKL expression by directly cooperating with CRKL. Our study uncovered a novel ETV6-miR-429-CRKL regulatory circuitry in maintaining the aggressive phenotypes of HCC and partially elucidated the molecular mechanism of HCC metastasis.

\section{Materials and methods}

\section{Patients and tissue samples}

Sixteen pairs of matched tumor tissues and corresponding non-tumor liver tissues from hepatocarcinoma patients were collected from the Division of Hepatobiliary and Pancreatic Surgery, Department of Surgery, The Second Affiliated Hospital of Dalian Medical University, Dalian, China. None of the patients had received radiotherapy or chemotherapy before tissue collection. There were 11 men and 5 women, 7 patients of age $\geq 60$ years and 9 patients of age $<60$ years; 8,4 and 4 patients are cataloged into T1, T2 and T3 stages; 12 patients are primary $\mathrm{HCC}$ and 4 patients unknown; 1 patient exhibits perineuronal invasion, 10 patients no perineuronal invasion and 5 patients unknown; 5 patients have satellite nodules, 4 patients without satellite nodules and 7 patients unknown; 8 patients are HBV (hepatitis B virus) positive and 8 patients unknown; 1 patient of AFP (alpha fetoprotein) $\leq 20 \mathrm{IU} / \mathrm{ml}, 5$ patients of $20<$ AFP $\leq$ $400 \mathrm{IU} / \mathrm{ml}, 3$ patients of AFP $>400 \mathrm{IU} / \mathrm{ml}$ and 7 patients unknown. Tissue specimens were frozen in liquid nitrogen immediately after surgical resection and stored at $-80^{\circ} \mathrm{C}$ until use. The use of human tissues and the study protocol was approved by the Medical Ethics Committee of Dalian Medical University, and informed consent was obtained from all patients. All experiment methods were performed in accordance with the relevant guidelines and regulations.

\section{Cell culture}

Human normal liver LO2, hepatocellular carcinoma HepG2, HuH7, HCCLM3 and human embryonic kidney $293 \mathrm{~T}$ cells were purchased from the Shanghai Culture Collection of Chinese Academy of Sciences and cultured in 90\% Dulbecco's modified Eagle's medium (DMEM, Gibco, USA) supplemented with $10 \%$ fetal bovine serum (FBS, TransGen, China), $100 \mathrm{U} / \mathrm{ml}$ penicillin and $100 \mathrm{U} / \mathrm{ml}$ streptomycin (Gibco, USA) in a humidified incubator at $37{ }^{\circ} \mathrm{C}$ with $5 \% \mathrm{CO}_{2}$.

\section{Western blotting (WB) assay}

Total protein was extracted from each group cells using radio-immunoprecipitation assay (RIPA) buffer $[50 \mathrm{mM}$ pH 8.0 Tris- $\mathrm{HCl}, 150 \mathrm{mM} \mathrm{NaCl}, 1 \%$ Triton X-100, $0.5 \%$ sodium deoxycholate, $0.1 \% \mathrm{SDS}$ in the presence of $1 \mathrm{mM}$ $\mathrm{Na}_{3} \mathrm{VO}_{4}, 1 \mu \mathrm{g} / \mathrm{ml}$ leupeptin and 0.5 mM PMSF (phenylmethanesulfonyl fluoride)]. The supernatant was collected by centrifugation at $12000 \mathrm{rpm}$ at $4{ }^{\circ} \mathrm{C}$ for $15 \mathrm{~min}$. Equal amounts of each group of protein samples determined by Bradford assay were boiled for $5 \mathrm{~min}$ in loading buffer and separated by 10\% SDS-PAGE (sodium dodecyl sulfate-polyacrylamide gel electrophoresis). The protein bands were transferred onto a nitrocellulose (NC) membrane (PALL, USA), blocked with 5\% (w/v) skim milk (BD, USA) in TBST (Tris-buffered-saline-tween 20, $\mathrm{pH} 7.5,100 \mathrm{mM} \mathrm{NaCl}, 50 \mathrm{mM}$ Tris and 0.1\% Tween20) for $3 \mathrm{~h}$ at room temperature (RT) and then incubated with primary antibodies at $4{ }^{\circ} \mathrm{C}$ overnight. The primary antibodies were CRKL (1:2000, Santa Cruz Biotechnology, USA), ETV6 (1:400, Abcam, USA), ACTB ( $\beta$-actin, 1: 4000, Sanying, China) and GAPDH (glyceraldehyde-3phosphate dehydrogenase, 1:4000, Proteintech, USA). The $\mathrm{NC}$ membrane was then washed with TBST for $3 \times 10$ min, incubated with the secondary antibody conjugate for $3 \mathrm{~h}$ at RT and washed again with TBST $3 \times 10 \mathrm{~min}$. 
Protein bands were visualized by electrochemiluminescence (ECL, Advansta, USA) and analyzed using the Bio$\operatorname{Rad}_{\text {ChemiDoc }}{ }^{\text {Tn }}$ MP system (Bio-Rad, USA). GAPDH and $\mathrm{ACTB}$ were used as internal references.

\section{Immunohistochemistry (IHC) assay}

IHC assay was used to determine the expression levels of CRKL (1:2000, Santa Cruz Biotechnology, USA) in HCC tissue arrays. Tissue sections were treated with biotin-streptavidin horseradish peroxidase (HRP) detection systems (ZSGB-BIO, China) according to the manufacturer's protocol. The images were visualized with a DAB (diaminobenzidin) kit (ZSGB-BIO, China) using a BX63 microscope (Olympus, Japan). IHC immunoreaction intensity was rated into four grades, 0 (negative), 1 (weak), 2 (moderate) and 3 (strong) as Score I. Moreover, based on the detected positively staining cells, $\mathrm{DAB}$ staining quantity of each sample was graded as 0 (none), 1 (1-10\% cells per field), 2 (10-50\%), 3 (51$75 \%)$ and $4(>76 \%)$ as Score II. The multiplication of Score I by Score II ranging from 0 to 12 was used as a measure of IHC immunoreactivity degree. The scores of $0-2,3-5,6-8$, and $9-12$ were considered as negative $(-)$, weak $(+)$, moderate $(++)$ and strong $(+++)$. IHC assays were scored separately by two independent experienced pathologists.

\section{Quantitative real-time PCR (qRT-PCR) assay}

Total RNA was extracted from each group of tissues and cells using Trizol $^{\mathrm{m}}$ reagent (Invitrogen, USA) and reversely transcribed into an EasyScript One-Step gDNA Removal and cDNA Synthesis SuperMix kit (TransGen, China). qRT-PCR was then performed using TransStart Tip Green qPCR SuperMix (TransGen, China) with a StepOnePlus ${ }^{\mathrm{mi}}$ Real-Time PCR system (ThermoFisher, USA). snRNA U6 was used as internal reference for miR-429. The relative expression levels of miR-429 in different groups of cells, and in paired tumor and paracancerous non-tumor tissues from hepatocarcinoma patients were compared using the $2^{-\triangle \Delta C T}$ method.

\section{Plasmid construction and lentivirus infection}

Previously, we constructed the recombinant PCDH-EF1MCS-T2A-Puro-CRKL expression vector to overexpress CRKL in HCC cell lines [26]. To overexpress ETV6 in HCC cell lines, the full-length coding sequence of ETV6 was first amplified by RT-PCR using forward primer $5^{\prime}$ TAGCTAGCGCCACCATGTCTGAGACTCCTGCTC3' and reverse primer 5' - GCCGCGCTTCGAATCAGCATTCATCTTCTTGG-3', then inserted into the Nhe I and $B s t B$ I sites of a PCDH-EF1-MCS-T2A-Puro vector. The recombinant expression vector PCDH-EF1-MCST2A-Puro-ETV6 was used for overexpressing ETV6 in cells, the empty vector PCDH-EF1-MCS-T2A-Puro was used as control.

Lentivirus packaging was performed according to the manufacturer's instructions, the recombinant expression vectors of PCDH-EF1-MCS-T2A-Puro-CRKL, PCDHEF1-MCS-T2A-Puro-ETV6, PCDH-EF1-MCS-T2A-Puro were separately mixed with the packaging plasmids psPAX2 and pMD2G, and transfected into $293 \mathrm{~T}$ cells using Lipofectamine 2000 (Invitrogen, USA) for $48 \mathrm{~h}$. The virus particle supernatants were harvested by centrifugation at $4500 \mathrm{rpm}$ for $10 \mathrm{~min}$ and filtered with a $0.22 \mu \mathrm{m}$ microporous membrane. Then, $1 \times 10^{5}$ HepG2, HCCLM3 and $\mathrm{HuH} 7$ cells were infected with lentivirus in 6-well plates containing $8 \mu \mathrm{g} / \mathrm{ml}$ polybrene (Solarbio, China) for $48 \mathrm{~h}$ in a humidified incubator at $37^{\circ} \mathrm{C}$ with $5 \% \mathrm{CO}_{2}$. The cells stably transfected with PCDH-EF1-MCS-T2A-PuroCRKL, PCDH-EF1-MCS-T2A-Puro-ETV6 and PCDHEF1-MCS-T2A-Puro were screened against $0.5 \mu \mathrm{g} / \mathrm{ml}$ puromycin for $21 \mathrm{~d}$ at $37^{\circ} \mathrm{C}$ with $5 \% \mathrm{CO} 2$.

\section{siRNA design and transient transfection}

For CRKL and ETV6 knockdown, targeting siRNAs (small interfering RNA) were designed according to CRKL sequence (Genbank: NM_005207.3, siCRKL: 5' GTCACAAGGATGAATATAA-3') and ETV6 sequence (Genbank: NM_001987.4; siETV6-1: 5' -CAATATAGGT CTCAGAAATCC-3'; siETV6-2: 5'-GCATTAAGCAGG AACGAAT-3'; siETV6-3: 5'-GGGATTACGTCTATCA GTT-3') using Invitrogen, siDirect and Whitehead software. Meanwhile, one siRNA with non-targeting sequence 5' -TTCTCCGAACGTGTCACGT-3' was designed as a negative control (NC). One day before transfection, $3 \times$ $10^{5}$ cells/well in $2 \mathrm{ml}$ DMEM supplemented with $15 \%$ FBS were seeded into a 6-well plate, and the siRNA mixtures $(2 \mu \mathrm{l}$ siETV6-1 $+2 \mu \mathrm{l}$ siETV6- $2+2 \mu \mathrm{l}$ siETV6-3) were transfected into HepG2, HCCLM3 and HuH7 cells using $5 \mu$ Lipofectamine 2000 (Invitrogen, USA) according to the manufacturer's instructions for $48 \mathrm{~h}$ at $37^{\circ} \mathrm{C}$ with $5 \%$ $\mathrm{CO}_{2}$, respectively.

\section{In vitro cell migration and invasion assays}

The effect of CRKL and ETV6 deregulations on the migration and invasion abilities of HepG2, HCCLM3 and $\mathrm{HuH7}$ cells were examined using the Boyden transwell chamber assay. Briefly, $1 \times 10^{4}$ cells in $200 \mu \mathrm{l}$ serum-free DMEM were seeded onto the upper compartment of transwell with $8 \mu \mathrm{m}$ pore size polycarbonate filters (Corning, USA). The chambers were then placed into 24-well plates containing $600 \mu \mathrm{l}$ DMEM with $20 \%$ FBS and incubated for $24 \mathrm{~h}$ at $37{ }^{\circ} \mathrm{C}$ with $5 \% \mathrm{CO}_{2}$. For invasion assay, the inserts were first coated with $50 \mu \mathrm{l} 2.5 \%$ ECM gel (Sigma, USA) in DMEM, and incubated at $37^{\circ} \mathrm{C}$ for $1 \mathrm{~h} .1 \times 10^{4}$ cells in $200 \mu \mathrm{l}$ serum-free DMEM were seeded onto the upper compartment of the 
transwell. The chambers were then placed into 24-well plates containing $600 \mu \mathrm{l}$ DMEM with $20 \% \mathrm{FBS}$ and incubated for $24 \mathrm{~h}$ at $37^{\circ} \mathrm{C}$ with $5 \% \mathrm{CO}_{2}$. The non-migrated and non-invaded cells on the upper surface of the insert were removed by swabbing, the migrated and invaded cells onto the lower surface were fixed with methanol (AR, Sigma, US) for $30 \mathrm{~min}$, stained with $0.1 \%$ crystal violet for $40 \mathrm{~min}$, washed with phosphate buffered solution (PBS), counted using an upright light microscope (Olympus, Japan) with $100 \times$ magnification. Five random field views were counted and averaged.

\section{F-actin cytoskeleton staining assay}

The TRITC (tetramethyl rhodamin isothiocyanate)-Phalloidin staining assay was performed to investigate the influence of CRKL and ETV6 on the cytoskeleton structure of HepG2, HCCLM3 and HuH7 cells. The $0.17 \mathrm{~mm}$ thick round cover glasses of $25 \mathrm{~mm}$ diameter were placed into 6-well plates, then $1 \times 10^{5}$ cells from each group were seeded into the cover glasses and cultured for $24 \mathrm{~h}$ at $37^{\circ} \mathrm{C}$ in humidified incubator with $5 \%$ $\mathrm{CO}_{2}$. The cover glasses were then twice washed with 1 $\mathrm{ml}$ PBS, fixed in $4 \%$ paraformaldehyde for $10 \mathrm{~min}$ at RT, washed 3 times with PBS, permeabilized with acetone, and continuously incubated in $100 \mu \mathrm{l}$ TRITC-Phalloidin $(400 \mathrm{nM})$ containing $1 \%$ bovine serum albumin (BSA) for $30 \mathrm{~min}$ in the dark at RT. The cover glasses were washed with PBS for 3 times and counterstained in $100 \mu \mathrm{l} 50 \mathrm{nM}$ Hoechst 33342 staining solution (Sigma, USA) for cell nucleus. Images were immediately taken using a fluorescence microscope (Olympus, Japan) at five randomly selected visual fields of $1000 \times$ within $1 \mathrm{~h}$.

\section{Co-immunoprecipitation assay}

Co-immunoprecipitation (Co-IP) assay was performed to determine the interaction between CRKL and ETV6. Total protein was extracted from $5 \times 10^{6}$ HCCLM3PCDH-CRKL or HCCLM3-PCDH-NC cells using RIPA buffer, then $500 \mu \mathrm{g}$ protein was incubated with $2 \mu \mathrm{l}$ antiCRKL (Santa Cruz Biotechnology, USA), $2 \mu$ anti-ETV6 (abcam, USA), or $1 \mu \mathrm{l}$ nonspecific anti-rabbit IgG (Santa Cruz Biotechnology, USA) for $1 \mathrm{~h}$ at $4{ }^{\circ} \mathrm{C}$. The immune complexes were pulled down by $20 \mu \mathrm{l}$ protein $\mathrm{A} / \mathrm{G}$ agarose beads (Santa Cruz Biotechnology, USA) at $4{ }^{\circ} \mathrm{C}$ overnight. Then the beads were washed 3 times with $500 \mu \mathrm{l}$ RIPA buffer at RT, and after centrifugation with 12,000 rpm for $15 \mathrm{~min}$ at $4{ }^{\circ} \mathrm{C}$, the beads were mixed with $4 \mu \mathrm{l}$ $5 \times$ SDS-PAGE loading buffer and $16 \mu$ RIPA and boiled for $10 \mathrm{~min}$. Then the immunoprecipitated proteins were separated by $10 \%$ SDS-PAGE and analyzed by WB.

\section{Chromatin immunoprecipitation (ChIP) assay}

ChIP assay was performed to investigate the interaction between ETV6 and miR-429 using an EZ-ChIP ${ }^{\text {mix }}$
Chromatin Immunoprecipitation Kit (Millipore, USA). Briefly, $2 \times 10^{7}$ HCCLM3 cells were cross-linked with $550 \mu \mathrm{l} 37 \%$ formaldehyde for $10 \mathrm{~min}$ at RT and treated with $2 \mathrm{ml} 10 \times$ glycine for $5 \mathrm{~min}$ at RT, then the cells were washed with $2 \mathrm{ml}$ PBS containing $10 \mu \mathrm{l}$ protease inhibitor cocktail II, scraped and lysed with $1 \mathrm{ml}$ SDS lysis buffer containing $5 \mu \mathrm{l}$ protease inhibitor cocktail II. Then the lysates were sonicated on ice for $6 \times 15 \mathrm{~s}$ to shear the DNA and the debris was removed by centrifugation at $12000 \mathrm{rpm}$ for $10 \mathrm{~min}$ at $4{ }^{\circ} \mathrm{C}$. A small part of the lysate was used as DNA input control, the remaining part was diluted 10-fold with dilution buffer and incubated with $4 \mu \mathrm{l}$ anti-ETV6 (Abcam, USA) or $1 \mu \mathrm{l}$ anti-RNA polymerase II, $1 \mu \mathrm{l}$ normal mouse IgG, $4 \mu \mathrm{l}$ anti-rabbit IgG at $4{ }^{\circ} \mathrm{C}$ overnight. Immunoprecipitated complexes were collected using $60 \mu \mathrm{l}$ protein $\mathrm{A} / \mathrm{G}$ agarose beads at $4{ }^{\circ} \mathrm{C}$ for $1 \mathrm{~h}$. After centrifugation at $5000 \mathrm{rpm}$ for $1 \mathrm{~min}$ at $4{ }^{\circ} \mathrm{C}$, the precipitates were washed with $1 \mathrm{ml}$ washing buffer at $4{ }^{\circ} \mathrm{C}$ for $3 \times 5 \mathrm{~min}$, and eluted with elution buffer $(20 \%$ SDS and $1 \mathrm{M} \mathrm{NaHCO}_{3}$ ) for $15 \mathrm{~min}$ at RT. Cross-linking of protein-DNA complexes was reversed with $8 \mu \mathrm{l} 5 \mathrm{M}$ $\mathrm{NaCl}$ at $65^{\circ} \mathrm{C}$ overnight, followed by treatment with $1 \mu \mathrm{l}$ RNase A at $37^{\circ} \mathrm{C}$ for $30 \mathrm{~min}$, and $4 \mu \mathrm{l} 0.5 \mathrm{M}$ EDTA, $8 \mu \mathrm{l}$ $1 \mathrm{M}$ Tris- $\mathrm{HCl}, 1 \mu \mathrm{l}$ Proteinase $\mathrm{K}$ at $45^{\circ} \mathrm{C}$ for $2 \mathrm{~h}$. Then, DNA was extracted using a spin column according to the manufacturer's instructions. The DNA was subjected to PCR to amplify the 262 bp promoter region of miR-429 using specifically the designed primers, $\mathrm{F}$ : $5^{\prime}$-ACCTCG CCACCGCCTCCCATTGTCCCGTCG-3' and R: 5'-TG CCAGGCCCGGGTGGGTGTGAACCGGCTTC-3'.

\section{Data processing and statistical analysis}

Statistical analyses were performed using GraphPad Prism 5.0 software. The data were presented as mean \pm SD of at least three independent experiments. The statistical differences between groups were evaluated by Student's t-test analysis. As most of the distributions deviated from the normal Gaussian distribution, non-parametric tests were used for further analyses. The correlations between the expression of ETV6, CRKL and miR-429 were analyzed using the Spearman's rank correlation coefficient. Differences with $P \leq 0.05$ are statistically significant.

\section{Results \\ Expression patterns and the correlations of ETV6, CRKL and miR-429 in hepatocarcinoma patients' tumorous tissues and HCC cell lines}

To investigate the potential role of ETV6, CRKL and miR-429 in hepatocarcinoma, we detected the expression levels of ETV6, CRKL and miR-429 in HCC tissues and cells. WB results showed that compared with nontumor liver tissues, ETV6 expression in tumorous tissues of hepatocarcinoma patients was increased by $127.6 \%$ $(P=0.0005$, Fig. 1a). Meanwhile, ETV6 was expressed in 


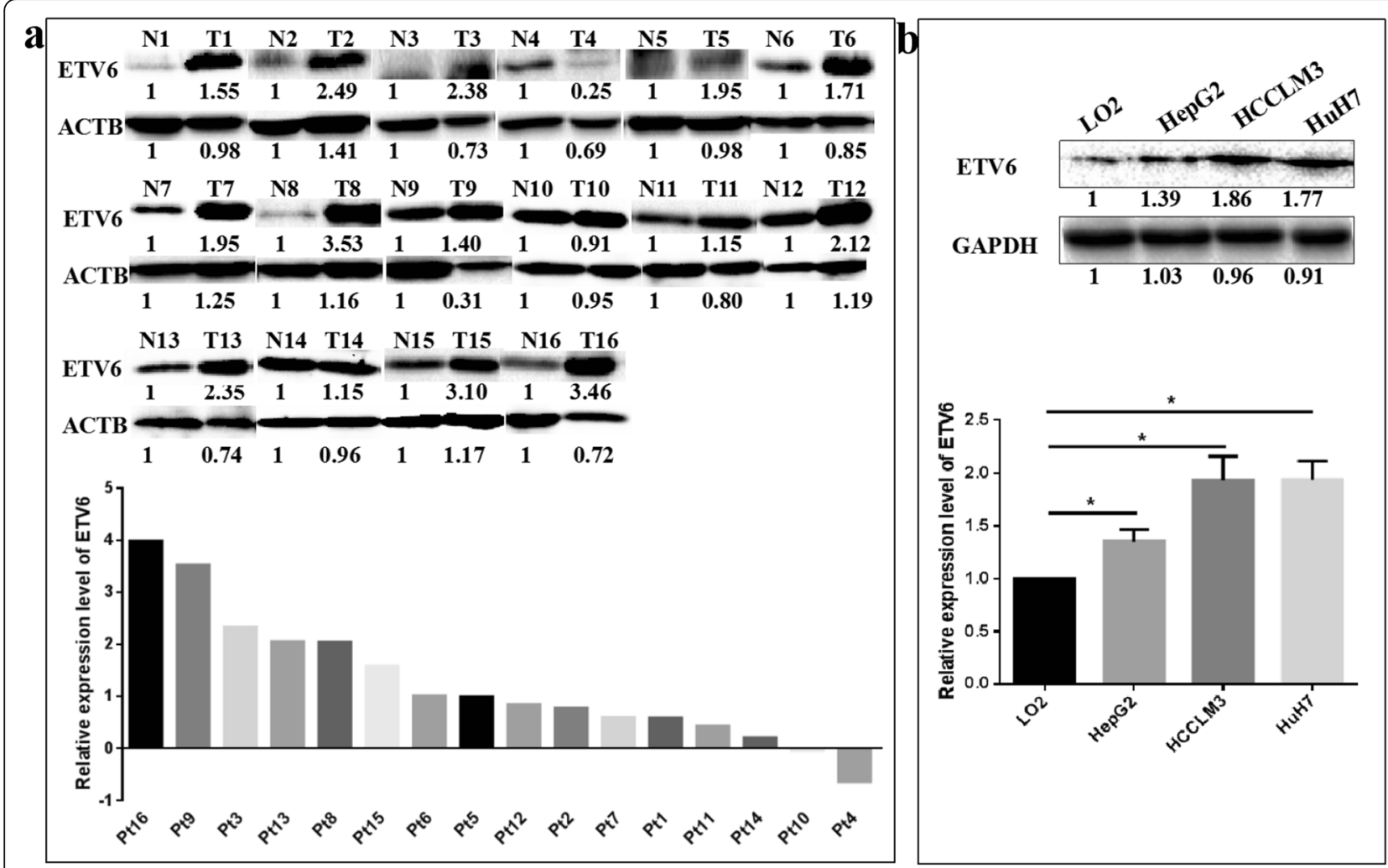

Fig. 1 The expression patterns of ETV6 in hepatocarcinoma patients' tumorous tissues and HCC cells. a WB measured the protein expression level of ETV6 in hepatocarcinoma patients' tumorous tissues and corresponding non-tumor liver tissues. ETV6 was overexpressed in hepatocarcinoma patients' tumorous tissues. b WB measured the protein expression level of ETV6 in HCC HepG2, HCCLM3 HuH7 cells and human normal liver LO2 cells. ETV6 was overexpressed in HCC cells

all the tested cell lines and a comparatively low expression was shown in normal liver LO2 cells compared with the hepatocarcinoma cells. Compared with normal liver LO2 cells, the expression levels of ETV6 in HepG2, HCCLM3 and HuH7 cells were increased by $34.9 \%(P=$ 0.0499, Fig. 1b), $93.3 \%(P=0.0284$, Fig. $1 \mathrm{~b})$ and $94.0 \%$ $(P=0.0166$, Fig. 1b). Our results suggested that ETV6 displayed a comparatively high expression in hepatocarcinoma tissues and cells, and that it might be a potential biomarker for hepatocarcinoma progression.

CRKL was also upregulated in hepatocarcinoma patients' tumorous tissues and hepatocarcinoma cell lines. As shown in Fig. 2a, WB assay showed CRKL expression was upregulated by $79.6 \%(P=0.0041)$ in the tumorous tissues from hepatocarcinoma patients. Meanwhile, CRKL expression levels were increased by $47.2 \%(P=$ $0.0221), 101.7 \%(P=0.0068)$ and $85.5 \%(P=0.0134)$ in HepG2, HCCLM3 and HuH7 cells compared with LO2 cell (Fig. 2b). A tissue microarray composed of 48 paired tumorous and adjacent normal tissues from HCC patients was further employed to address the expression alteration of CRKL by IHC. Among the 48 cases with hepatocarcinoma, 28 showed strong, 15 showed moderate, 5 showed weak and 0 showed negative CRKL expression. The positive immunostaining rate of CRKL in hepatocarcinoma tissues was 2.15 -fold compared to adjacent normal tissues (Table 1). The representative examples for CRKL expression in hepatocarcinoma tissues and adjacent normal tissues were shown in Fig. 2c. These results demonstrated the overexpression of CRKL in hepatocarcinoma and indicated the likelihood of its high expression being involved in the development and progression of hepatocarcinoma.

Furthermore, we measured that miR-429 was significantly down-regulated in the tumorous tissues of hepatocarcinoma patients and in hepatocarcinoma cell lines. As shown in Fig. 3a, qRT-PCR assays showed that the miR-429 expression level was downregulated by $27.5 \%(P=0.0136)$ in the tumorous tissues from hepatocarcinoma patients. Furthermore, miR-429 was expressed in all the tested cell lines and a comparatively high expression was shown in normal liver LO2 cells compared to hepatocarcinoma cells. miR-429 expression levels were decreased by $83.0 \%(P=0.0002)$, 93.3\% $(P<0.0001)$ and $95.1 \%(P<0.0001)$ in HepG2, HCCLM3 and HuH7 cells compared with LO2 cell (Fig. 3b). Taken together, our results indicated that ETV6, CRKL might act as tumor promoters and miR-429 


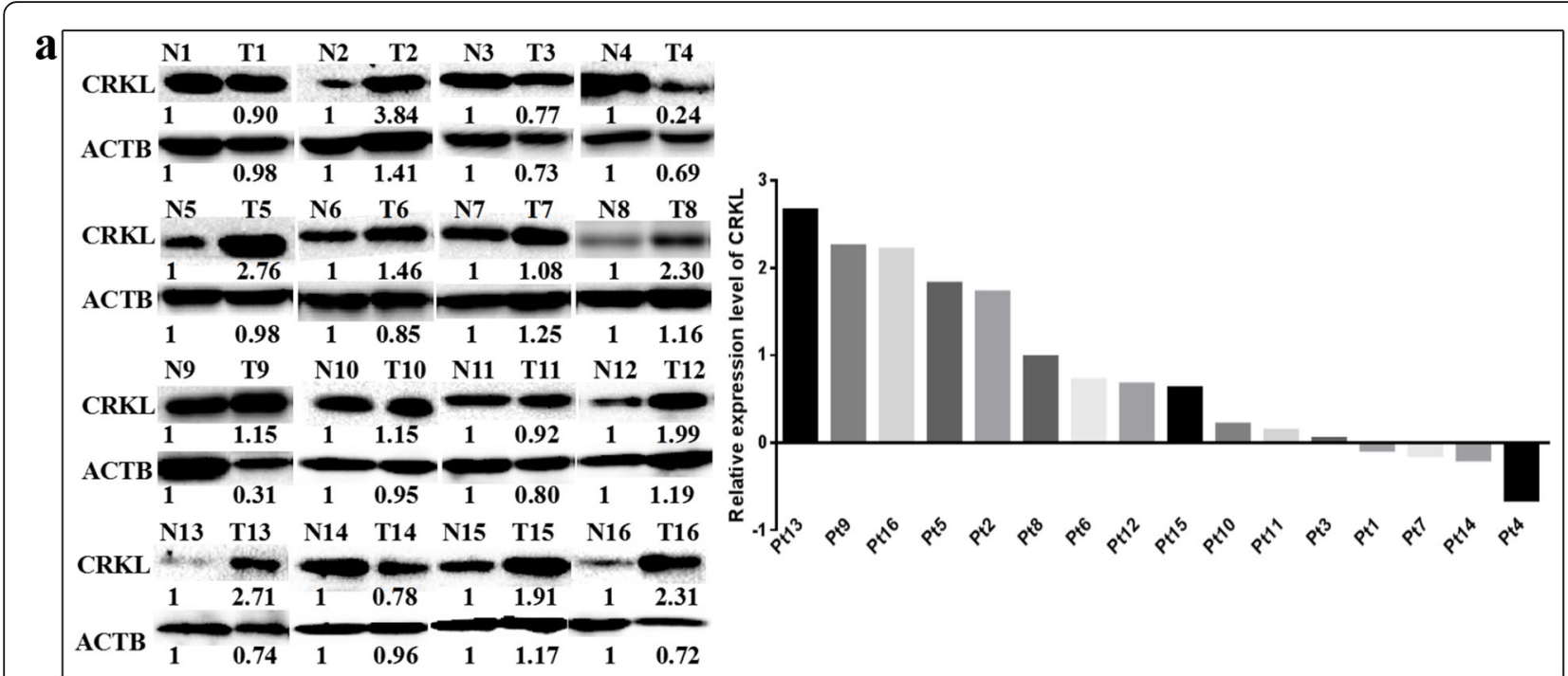

b
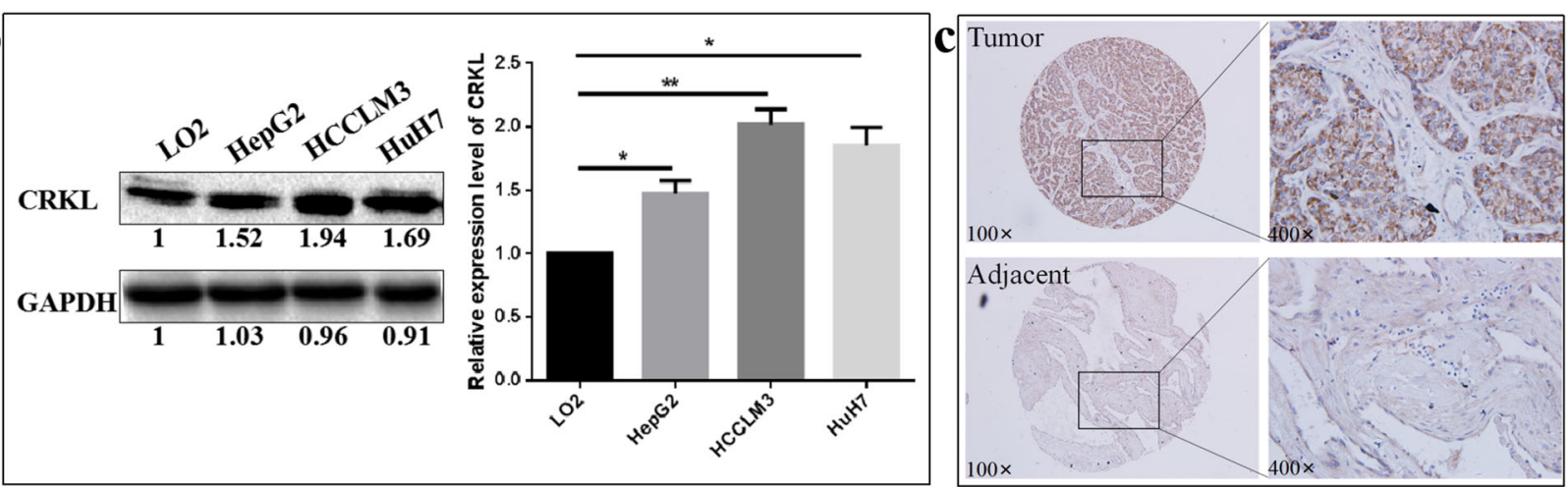

Fig. 2 The expression patterns of CRKL in hepatocarcinoma patients' tumorous tissues and HCC cells. a WB measured the protein expression level of CRKL in hepatocarcinoma patients' tumorous tissues and corresponding non-tumor liver tissues. CRKL was overexpressed in hepatocarcinoma patients' tumorous tissues. b WB measured the protein expression level of ETV6 in HCC HepG2, HCCLM3 HuH7 cells and human normal liver LO2 cells. CRKL was overexpressed in HCC cells. $\mathbf{c} \| \mathrm{HC}$ measured the protein expression level of CRKL in 48 paired tumorous and adjacent normal tissues from HCC patients

as a tumor suppressor involved in the development and progression of HCC.

We further analyzed the inter-correlations of ETV6, CRKL and miR-429 expression level changes in tumorous tissues of hepatocarcinoma patients and in hepatocarcinoma cells. As shown in Fig. 4a, the upregulations of ETV6 and CRKL were positively correlated in both hepatocarcinoma patients' tumorous tissues $\left(R^{2}=0.4955\right.$, $P=0.0136$, Fig. 4a) and in hepatocarcinoma cells $\left(R^{2}=\right.$ 0.9604, $P=0.0200$, Fig. 4a). The CRKL expression level change was negatively correlated with miR-429 in both

Table 1 CRKL was overexpressed in tumor tissues from $48 \mathrm{HCC}$ patients

\begin{tabular}{|c|c|c|c|c|c|c|}
\hline \multirow[t]{2}{*}{ Group } & \multirow[t]{2}{*}{ Total } & \multicolumn{4}{|c|}{ CRKL } & \multirow[t]{2}{*}{$P$} \\
\hline & & - & + & ++ & +++ & \\
\hline Tumor tissues & 48 & 0 & 5 & 15 & 28 & 0.008 \\
\hline Adjacent tissues & 48 & 0 & 5 & 30 & 13 & \\
\hline
\end{tabular}

hepatocarcinoma patients' tumorous tissues $\left(R^{2}=0.4754\right.$, $P=0.0031$, Fig. 4b) and in hepatocarcinoma cells $\left(R^{2}=\right.$ 0.9713, $P=0.0144$, Fig. 4b). A negative correlation was also established for ETV6 upregulation with miR-429 downregulation in both hepatocarcinoma patients' tumorous tissues $\left(R^{2}=0.3090, P=0.0254\right.$, Fig. $\left.4 \mathrm{c}\right)$ and in hepatocarcinoma cells $\left(R^{2}=0.9655, P=0.0174\right.$, Fig. 4c) Our results demonstrated that ETV6 expression is positively correlated with CRKL expression, while miR-429 expression is simultaneously negatively correlated with CRKL and ETV6 expression, and the dysexpressions of ETV6, CRKL and miR-429 were closely correlated in affecting hepatocarcinoma malignancy.

ETV6 deregulation affects the in vitro migration, invasion and cytoskeleton arrangement of HCC cells

To confirm its tumor promotion effect in HCC, we measured both the overexpression and knockdown of ETV6 on the migration and invasion capacities of HCCLM3 

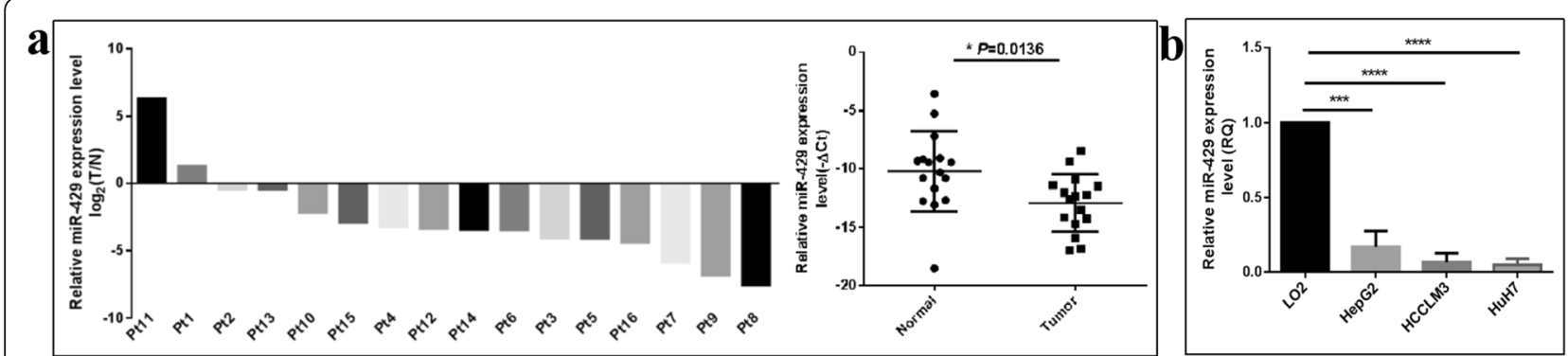

Fig. 3 The expression patterns of miR-429 in hepatocarcinoma patients' tumorous tissues and HCC cells. a qRT-PCR measured the expression level of miR-429 in in hepatocarcinoma patients' tumorous tissues and corresponding non-tumor liver tissues. miR-429 was poorly expressed in hepatocarcinoma patients' tumorous tissues. b qRT-PCR measured the expression level of miR-429 in HepG2, HCCLM3, HuH7 and LO2 cells. miR429 was poorly expressed in HCC cells
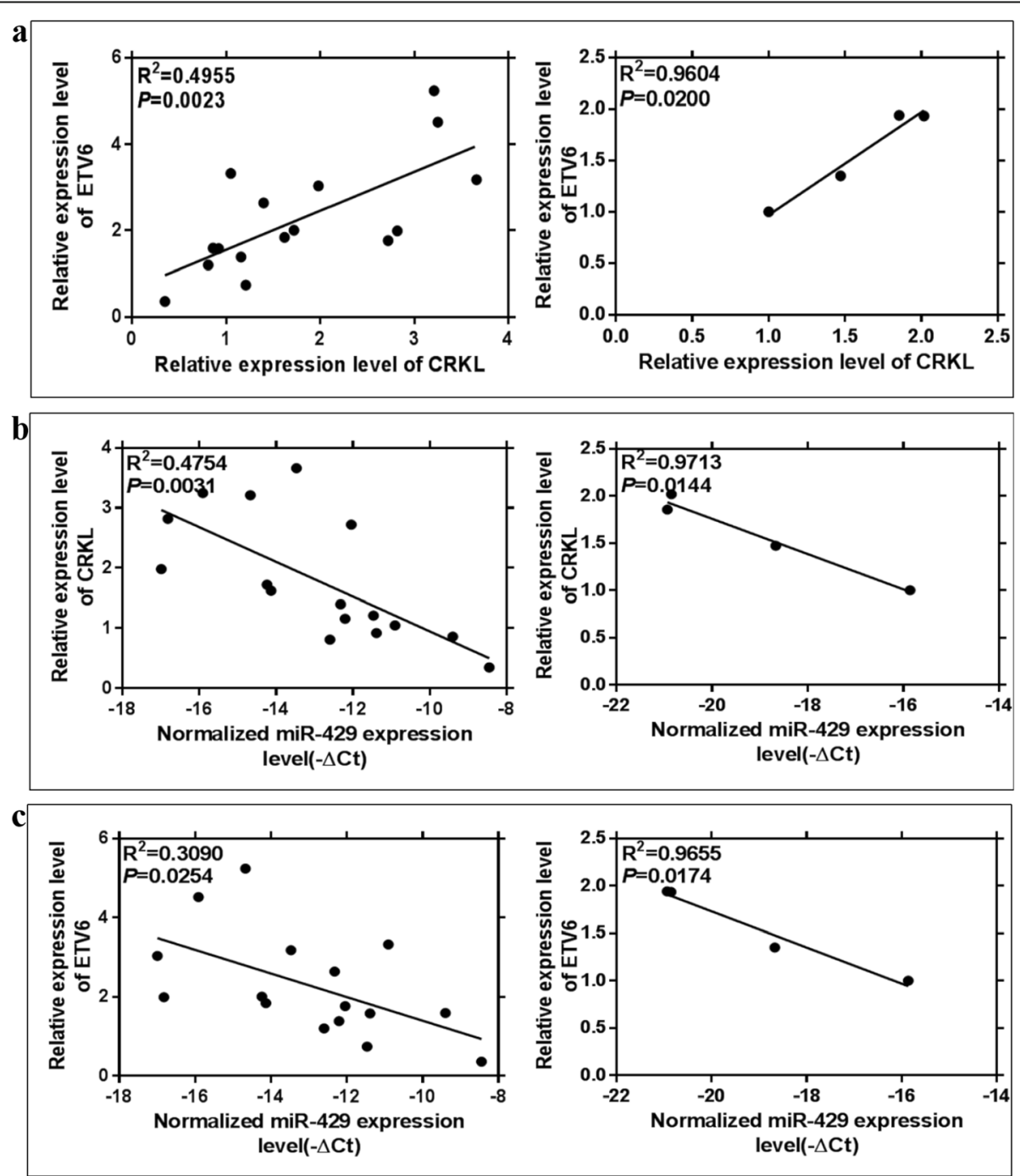

Fig. 4 The correlations of ETV6, CRKL and miR-429 expression level changes in hepatocarcinoma. a ETV6 expression level was positively correlated with CRKL expression in both hepatocarcinoma patients' tumorous tissues and in hepatocarcinoma cells. $\mathbf{b}$ CRKL expression level was negatively correlated with miR-429 expression in both hepatocarcinoma patients' tumorous tissues and in hepatocarcinoma cells. c ETV6 expression level was negatively correlated with miR-429 expression in both hepatocarcinoma patients' tumorous tissues and in hepatocarcinoma cells 
and $\mathrm{HuH7}$ cells. First, we successfully overexpressed ETV6 in HCCLM3 and HuH7 cells stably transfected with PCDH-EF1-MCS-T2A-Puro-ETV6 recombinant vector by Lentivirus infection against puromycin screening. In comparison with HCCLM3-PCDH and HuH7PCDH cells, ETV6 protein expression levels were increased by $99.7 \%(P=0.0084)$ and $61.7 \%(P=0.003)$ in HCCLM3-PCDH-ETV6 and HuH7-PCDH-ETV6 cells, respectively (Fig. 5a). The establishment of HCCLM3PCDH-ETV6 and HuH7-PCDH-ETV6 cells with stable ETV6 overexpression provides a control study for the upregulation effect of ETV6 on the malignant behaviours HCCLM3 and HuH7 cells. Meanwhile, we knockdown ETV6 expression in HCCLM3 and HuH7 cells using siETV6 transient transfection. In comparison with HCCLM3-siNC and HuH7-siNC cells, ETV6 protein expression levels decreased by $61.3 \%(P=0.0002)$ and 45.3\% $(P=0.0044)$ (Fig. $5 b)$ in HCCLM3-siETV6 and HuH7-siETV6 cells, which provides a control study for investigating ETV6 suppression on the malignant behaviours of hepatocarcinoma cells.

ETV6 dysexpression apparently affects the in vitro migration and invasion capacities of HCCLM3 and HuH7 cells. ETV6 expression level was positively correlated with the migration and invasion abilities of HCCLM3 and $\mathrm{HuH7}$ cells. ETV6 overexpression enhanced the migration and invasion abilities of HCCLM3 and $\mathrm{HuH} 7$ (Fig. 5c). The numbers of migrated HCCLM3-PCDHETV6 $(106.2 \pm 1.1)$ and HuH7-PCDH-ETV6 $(88.4 \pm 3.8)$ cells increased by $86.0 \%(P=0.0001)$ and $125.6 \%(P=$ $0.0001)$ than those of HCCLM3-PCDH $(57.0 \pm 0.7)$ and HuH7-PCDH cells $(38.8 \pm 2.3)$. The numbers of invaded HCCLM3-PCDH-ETV6 (104.6 \pm 3.4) and HuH7-PCDHETV6 $(116.2 \pm 2.9)$ cells increased by $110.0 \%(P=0.0001)$ and $96.6 \%(P=0.0003)$ than those of HCCLM3-PCDH $(50.4 \pm 1.2)$ and HuH7-PCDH cells $(58.8 \pm 4.4)$. Consistently, ETV6 downregulation inhibited the migration and invasion abilities of HCCLM3 and $\mathrm{HuH} 7$ cells (Fig. 5d). The numbers of migrated HCCLM3-siETV6 (30.8 \pm 1.2$)$ and HuH7-siETV6 $(33.2 \pm 1.7)$ cells decreased by $48.3 \%$ $(P=0.0001)$ and $57.3 \%(P=0.0003)$ than HCCLM3-siNC $(59.8 \pm 1.7)$ and HuH7-siNC cells $(61.0 \pm 4.3)$. The numbers of invaded HCCLM3-siETV6 $(39.2 \pm 0.6)$ and HuH7siETV6 $(38.4 \pm 1.2)$ cells decreased by $32.8 \%(P=0.0001)$ and $45.9 \%(P=0.0003)$ than HCCLM3-siNC $(57.8 \pm 0.9)$ and HuH7-siNC cells $(88.8 \pm 1.2)$. Clearly, ETV6 significantly affected the in vitro migration and invasion abilities of HCCLM3 and HuH7 cells. Our results indicated that ETV6 acts as a tumor promoter in hepatocarcinoma by promoting the aggressiveness of tumor cells.

It is well established that cytoskeleton elements are closely related to cell movement. The changes of F-actin microfilament organization in HCCLM3 and $\mathrm{HuH} 7$ cells after ETV6 deregulation was investigated by fluorescence microscopy using FITC-labeled phalloidin. ETV6 deregulation significantly affected F-actin cytoskeleton protein expression of HCCLM3 and HuH7 cells. As shown in Fig. 5e, ETV6 overexpression resulted in an obvious increase of F-actin microfilament. HCCLM3-PCDHETV6 and HuH7-PCDH-ETV6 cells showed a regular array of actin filaments present along the cells that evenly radiated to the cell membrane from the nucleus. While, ETV6 knockdown decreased F-actin cytoskeleton protein expression and microfilament arrangement of HCCLM3 and HuH7 cells, HCCLM3-siETV6 and HuH7-siETV6 exhibited a reduced amount of F-actin and a disorganization of actin filaments. Our results showed ETV6 acts as a promoter for HCCLM3 and $\mathrm{HuH} 7$ cells migration and invasion by destructing its Factin cytoskeleton. Taken together, ETV6 deregulation affected the cytoskeleton F-actin expression and arrangement of HCCLM3 and HuH7 cells, which leads to its migration and invasion potentials.

\section{CRKL deregulation affects the in vitro migration, invasion and cytoskeleton arrangement of HCC cells}

Previously, we obtained monoclonal HepG2-shCRKL cells with stable CRKL knockdown and transiently transfected HepG2 cells with a PCDH-EF1-MCS-T2A-PuroCRKL expression plasmid for overexpressing CRKL to investigate the effects of CRKL deregulation on migration and invasion abilities of HepG2 cells. We found CRKL expression levels were positively related to the in vitro migration and invasion abilities of hepatocarcinoma HepG2 cells [26]. In the current study, we further measured the effects of CRKL expression level change on the migration, invasion and cytoskeleton of HCC cells by stably up-regulating CRKL in HepG2, HCCLM3 and $\mathrm{HuH7}$ cells. The stable transfection with $\mathrm{PCDH}-$ EF1-MCS-T2A-Puro-CRKL vector by Lentivirus infection, combined with puromycin screening led to the stable overexpression of CRKL in HepG2, HCCLM3 and $\mathrm{HuH} 7$ cells. No protein level change differences were observed for CRKL between HepG2 and HepG2-PCDH cells, HCCLM3 and HCCLM3-PCDH, or HuH7 and HuH7-PCDH cells (Fig. 6a). In comparison with empty vector transfected HepG2-PCDH, HCCLM3-PCDH and HuH7-PCDH cells, CRKL protein levels were increased by 310.1\% $(P=0.0106), 162.0 \%(P=0.0001)$ and $82.1 \%(P=$ 0.0004) in HepG2-PCDH-CRKL, HCCLM3-PCDH-CRKL and HuH7-PCDH-CRKL cells, respectively, (Fig. 6a). The establishment of HepG2-PCDH-CRKL, HCCLM3-PCDHCRKL and HuH7-PCDH-CRKL cells with stable CRKL overexpression provides a control study for the upregulation effect of CRKL on the malignant behaviours of HepG2, HCCLM3 and HuH7 cells.

CRKL levels were positively correlated with the migration and invasion capacities of HepG2, HCCLM3 and 

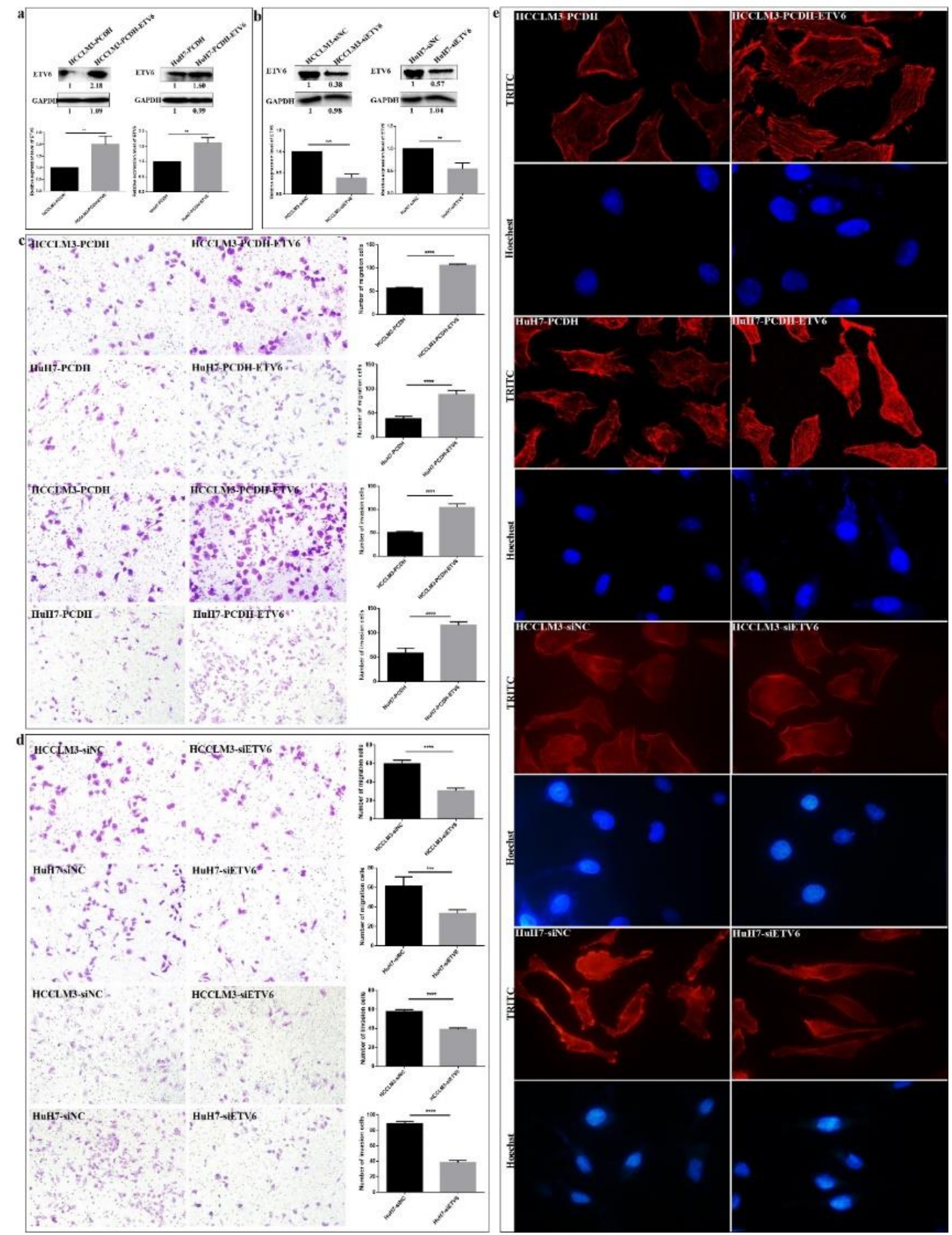

Fig. 5 (See legend on next page.) 
(See figure on previous page.)

Fig. 5 ETV6 dysexpression affects the in vitro migration, invasion and F-actin cytoskeleton expression and arrangement of HCC cells. a ETV6 were over-expressed in HCCLM3 and HuH7 cells stably transfected with PCDH-EF1-MCS-T2A-Puro-ETV6 vector by Lentivirus infection against puromycin screening. Relative ETV6 protein expression levels were determined by WB using GAPDH as the internal reference. b ETV6 were downregulated in HCCLM3 and HuH7 cells by siETV6 transient transfection interference. Relative protein levels were determined by WB using GAPDH as the internal reference. Transwell assays indicated ETV6 overexpression c enhanced and ETV6 knockdown $\mathbf{d}$ decreased the in vitro migration and invasion capacities of HCCLM3 and HuH7 cells. e FITC-phalloidin assays indicated ETV6 overexpression or downregulation increased or decreased cytoskeleton F-actin protein expression level and filament arrangement of HCCLM3 and HuH7 cells

HuH7 cells in vitro. CRKL overexpression promoted the migration and invasion abilities of HepG2, HCCLM3 and $\mathrm{HuH} 7$ cells. As shown in Fig. 6b, the numbers of migrated HepG2-PCDH-CRKL, HCCLM3-PCDH-CRKL and HuH7PCDH-CRKL cells were measured as $150.4 \pm 9.6,100.4 \pm$ $4.8,118.8 \pm 4.8$, which were increased by $122.5 \%(P<$ $0.0001), 77.4 \%(P=0.0004), 148.5 \%(P<0.0001)$ compared with HepG2-PCDH (69.2 \pm 4.8$)$, HCCLM3-PCDH (56.6 \pm 4.8) and HuH7-PCDH $(47.8 \pm 3.2)$ cells, respectively. The numbers of invaded HepG2-PCDH-CRKL (204.4 \pm 7.2$)$, HCCLM3-PCDH-CRKL $(100.4 \pm 5.8)$ and HuH7-PCDHCRKL $(137.8 \pm 6.9)$ cells increased by $108.6 \%(P<0.0001)$, 41.2\% $\quad(P=0.0004), \quad 88.3 \% \quad(P<0.0001) \quad$ compared with HepG2-PCDH (98.0 \pm 5.0$)$, HCCLM3-PCDH (69.4 \pm 5.3$)$ and $\mathrm{HuH7}-\mathrm{PCDH}(73.2 \pm 3.7)$ cells, respectively (Fig. 6c). Clearly, CRKL promoted the in vitro migration and invasion abilities of HepG2, HCCLM3 and HuH7 cells. Our results indicated that CRKL acts as a tumor promoter in hepatocarcinoma by promoting tumor cell's aggressiveness.

Furthermore, the TRITC-Phalloidin cytoskeleton staining assay indicated that CRKL overexpression resulted in an obviously increased intracellular microfilament of Factin and spreading lamellipodia in HepG2, HCCLM3 and HuH7 cells (Fig. 6d). HepG2-PCDH-CRKL, HCCLM3PCDH-CRKL and HuH7-PCDH-CRKL cells showed more abundant and ordered microfilaments, but the control group cells showed fewer and disordered actin. Our results showed CRKL acting as a promoter for HCCLM3 and $\mathrm{HuH} 7$ cells migration and invasion by destructing the F-actin cytoskeleton. Taken together, CRKL overexpression promoted $\mathrm{F}$-actin cytoskeleton protein expression and arrangement of HepG2, HCCLM3 and HuH7 cells, leading to its increased migration and invasion potential.

\section{ETV6 directly binds to CRKL to positively regulate its expression}

After, we observed a significant positive correlation between the expression levels of ETV6 and CRKL in hepatocarcinoma tumor tissues and hepatocarcinoma cell lines, then we investigated the mutual influence between the dysexpression of ETV6 and CRKL. CRKL overexpression increased endogenous ETV6 expression levels (Fig. 7a). In comparison with HepG2-PCDH, HCCLM3PCDH and HuH7-PCDH cells, ETV6 expression levels were increased by $118.5 \%(P=0.0372), 45.2 \%(P=0.0075)$,
51.5\% $(P=0.0338)$ in HepG2-PCDH-CRKL, HCCLM3PCDH-CRKL and HuH7-PCDH-CRKL cells. CRKL knockdown consistently resulted in decreased ETV6 expression by $37.0 \% \quad(P=0.0253), 33.9 \% \quad(P=0.0082), 26.7 \% \quad(P=$ 0.0295) in HepG2, HCCLM3 and HuH7 cells (Fig. 7b). Moreover, the effect of ETV6 expression level changes on CRKL were also investigated by transiently transfecting si-ETV6 in HepG2, HCCLM3 and HuH7 cells with CRKL overexpression. ETV6 downregulation decreased exogenous CRKL expression levels (Fig. 7c). Compared with HepG2-PCDH-CRKL-siNC, HCCLM3PCDH-CRKL-siNC, HuH7-PCDH-CRKL-siNC cells, CRKL protein expression levels were decreased by $28.9 \% \quad(P=0.0046), \quad 33.7 \% \quad(P=0.0224), \quad 19.1 \% \quad(P=$ 0.0181) in HepG2-PCDH-CRKL-siETV6, HCCLM3PCDH-CRKL-siETV6 and HuH7-PCDH-CRKL-siETV6 cells. The results demonstrated ETV6 expression was positively correlated with CRKL expression in hepatocarcinoma cells.

Tel-ABL fusion protein may form complexes with CRKL [10], and thus we proposed that ETV6 and CRKL might regulate each other directly by forming a complex. Co-IP experiment confirmed their direct interaction in HCCLM3 cells. The extracted proteins from HCCLM3-PCDH-CRKL and HCCLM3-PCDH cells were immunoprecipitated using antibody against CRKL, ETV6, and the control non-specific IgG, respectively, and the eluted proteins were detected by WB using antibody against ETV6, CRKL, the acetylated antibody, respectively. Our results clearly revealed that a CRKL protein band or ETV6 protein band appeared in the immunoprecipitated complexes with antibodies against ETV6 or CRKL, but not the non-specific IgG, meanwhile, the amount of CRKL-ETV6 complexes obtained was greater in HCCLM3-PCDH-CRKL cells than in HCCLM3PCDH cells (Fig. 7d). Our results indicated that ETV6 directly binds to CRKL to positively regulate its expression.

\section{ETV6 negatively regulates miR-429 by directly binding to its promoter region}

We observed a significant negative correlation between the expression level of ETV6 and miR-429 in hepatocarcinoma tumor tissues and hepatocarcinoma cell lines. To further confirm the negative correlation between ETV6 and miR-429 expression levels, we detected the effect of ETV6 knockdown on the expression level of miR- 


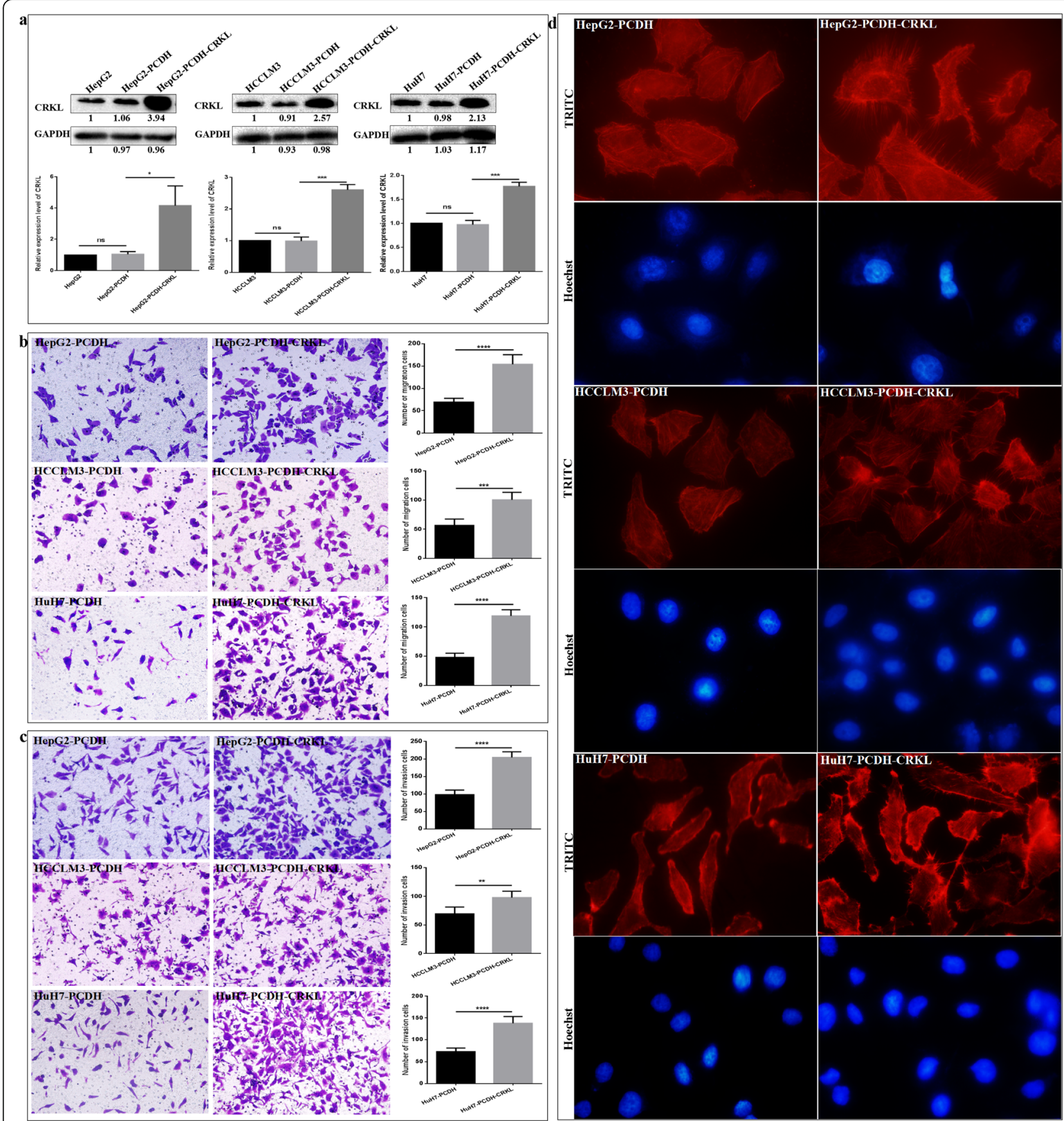

Fig. 6 CRKL overexpression affects the in vitro migration, invasion and F-actin cytoskeleton expression and arrangement of HCC cells. a CRKL were over-expressed in HepG2, HCCLM3 and HuH7 cells. PCDH-EF1-MCS-T2A-Puro-CRKL or PCDH-EF1-MCS-T2A-Puro were stably transfected into HepG2, HCCLM3 and HuH7 cells, screened against $0.5 \mu \mathrm{g} / \mathrm{ml}$ puromycin. Relative CRKL protein expression levels were determined by WB using GAPDH as internal reference. $\mathbf{b}$ and $\mathbf{c}$ Transwell assays showed that CRKL overexpression promoted the in vitro migration and invasion abilities of HepG2, HCCLM3 and HuH7 cells. d FITC-phalloidin assays showed that CRKL overexpression increased cytoskeleton F-actin protein expression and filament arrangement of HepG2, HCCLM3 and HuH7 cells

429 by transfecting si-ETV6 in CRKL-overexpression HepG2, HCCLM3 and HuH7 cells. ETV6 downregulation resulted in increased expression levels of miR-429 (Fig. 8a). In comparison with HepG2-PCDH-CRKLsiNC, HCCLM3-PCDH-CRKL-siNC and HuH7-PCDH-
CRKL-siNC cells, miR-429 expression levels were increased by 5.9 -fold $(P=0.0091)$, 8.4-fold $(P=0.0050)$ and 4.2-fold $(P=0.0031)$ in HepG2-PCDH-CRKLsiETV6, HCCLM3-PCDH-CRKL-siETV6 and HuH7PCDH-CRKL-siETV6 cells. Our results further 


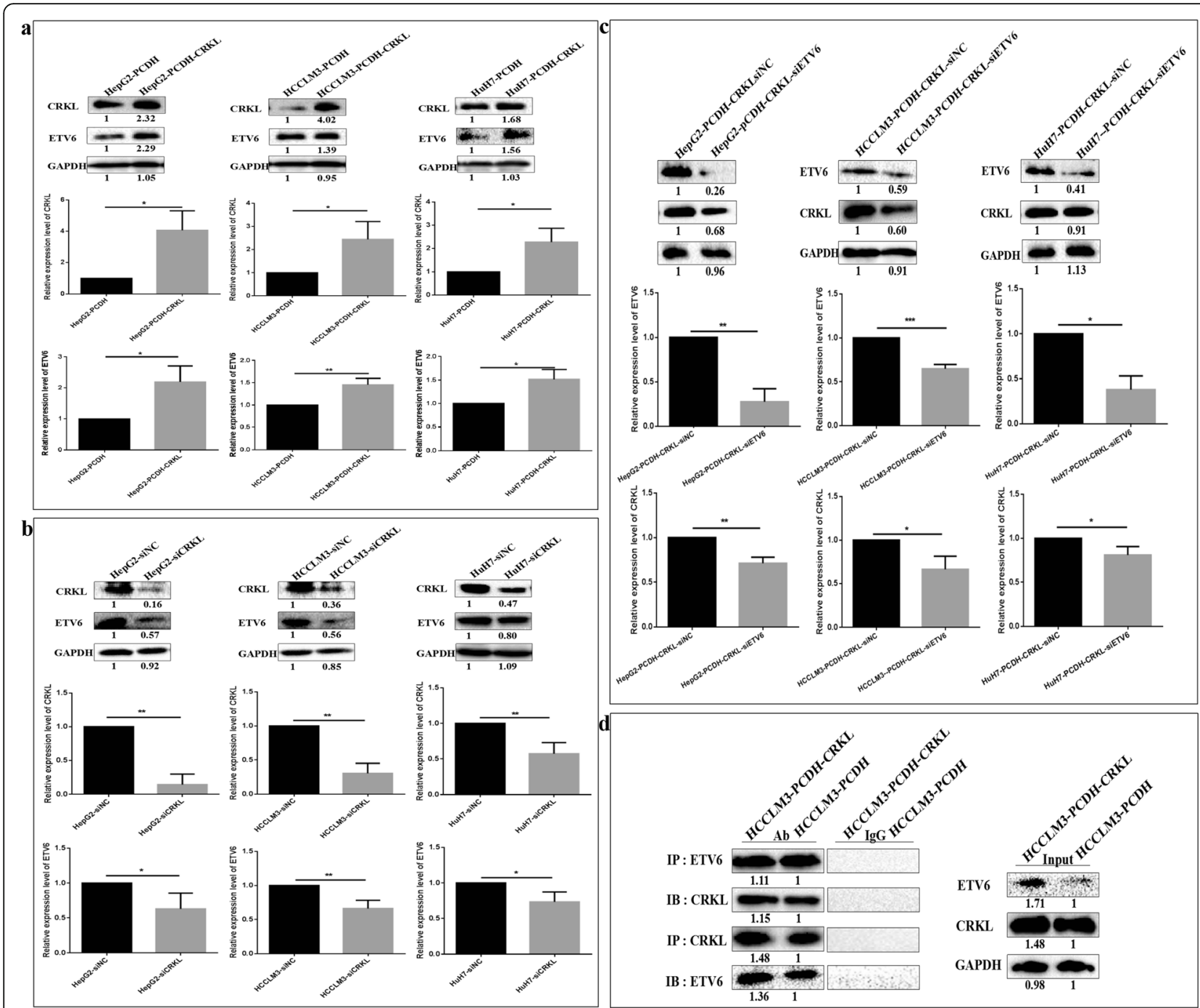

Fig. 7 ETV6 directly binds to CRKL and positively regulates its expression. a CRKL overexpression increased ETV6 expression levels in HepG2, HCCLM3 and HuH7 cells. b CRKL knockdown decreased ETV6 expression levels in HepG2, HCCLM3 and HuH7 cells. c ETV6 knockdown decreased CRKL expression levels in CRKL-overexpressing HepG2, HCCLM3 and HuH7 cells. d Co-IP assays detected the direct interaction between ETV6 and CRKL

demonstrated that ETV6 expression was negatively correlated with miR-429 expression.

Bioinformatics analysis software JASPAR (http://jaspar2 016.genereg.net/cgi-bin/jaspar_db.pl?rm=browse\&db=core\&tax_group=vertebrates) indicated that ETV6 protein potentially binds to the DNA promoter region at the 696705 site of miR-429 (Fig. 8b). A ChIP experiment was performed to verify the binding interaction using HCCLM3 cells. The miR-429 promoter region in the precipitated chromatin was amplified by PCR. As shown in Fig. 8c, the $262 \mathrm{bp}$ PCR product containing the binding site for ETV6 protein at the promoter region of miR-429 was specifically detected in anti-ETV6 ChIP and in the input ChIP, but not in anti-rabbit IgG ChIP. Meanwhile, the 166 bp PCR product of GAPDH promoter was observed in anti-RNA polymerase II ChIP, but not in the normal Mouse IgG ChIP. The above results indicated the direct binding of ETV6 to the promoter region of miR-429 mediates its functionality.

miR-429 negatively regulates CRKL expression by selectively targeting its $3^{\prime}$-UTR

We also observed a significant negative correlation between the expression levels of miR-429 and CRKL in hepatocarcinoma tumor tissues and hepatocarcinoma cell lines. To further confirm the negative correlation between miR-429 and CRKL, we detected the effect of CRKL deregulation on the expression levels of miR-429 in HepG2, HCCLM3 and HuH7 cells. CRKL overexpression decreased endogenous miR-429 expression level (Fig. 9a). In 

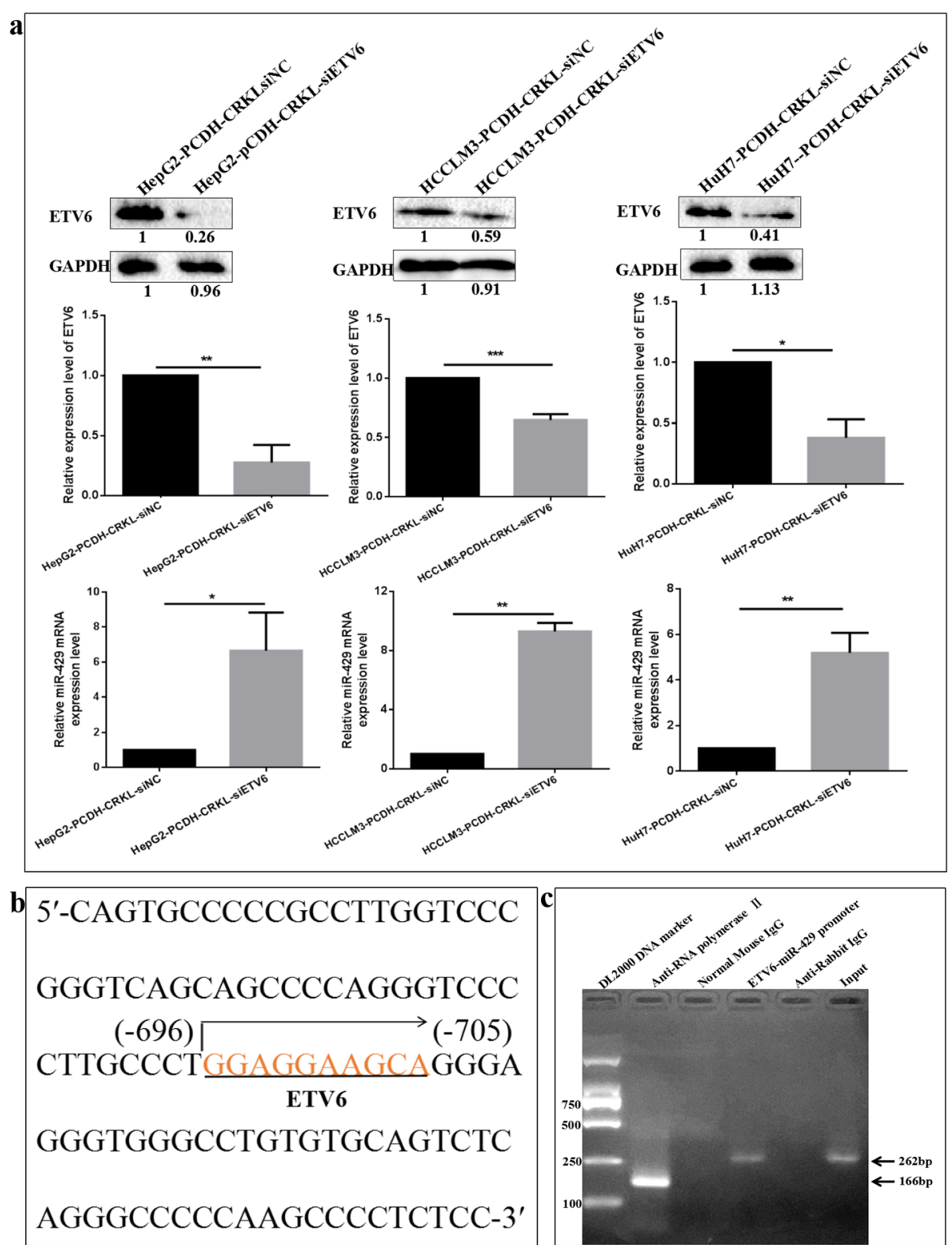

Fig. 8 ETV6 negatively regulates miR-429 by directly binding to its promoter region. a ETV6 downregulation increased miR-429 expression level in CRKL-overexpression HepG2, HCCLM3 and HuH7 cells. b Putative binding site for ETV6 protein at promoter region of miR-429. c ChIP assay of the binding of ETV6 to the promoter region of miR-429. Anti-RNA polymerase II was used as a positive control for binding to the GAPDH promoter region, normal mouse lgG was as a negative control for binding to the GAPDH promoter region, anti-ETV6 was used for experimental group on binding to the miR-429 promoter region, anti-rabbit lgG was used as a control. PCR products were analyzed by $1 \%$ agarose gel

comparison with HepG2-PCDH, HCCLM3-PCDH and HuH7-PCDH cells, miR-429 expression levels were decreased by $54.1 \%(P=0.0091), 41.5 \%(P=0.0311), 73.1 \%$ $(P=0.0030)$ in HepG2-PCDH-CRKL, HCCLM3-PCDHCRKL and HuH7-PCDH-CRKL cells. Consistently, CRKL knockdown resulted in increased endogenous miR-429 expression levels by $94.5 \%(P=0.0100), 90.1 \%(P=0.0462)$, 89.7\% $(P=0.0218)$ in HepG2, HCCLM3 and HuH7 cells (Fig. 9b). Our results further demonstrated miR-429 expression was negatively correlated with CRKL expression in hepatocarcinoma cells. Meanwhile, we have previous reported that CRKL was a direct downstream target of miR-429 via direct binding to site 2 in its 3 '-UTR by post-transcriptionally mediating its functionality, and miR-429 overexpression and suppression decreased and increased endogenous CRKL expression levels in HepG2 cells [26]. Our results indicated miR-429 negatively regulates CRKL expression by selectively targeting its 3 '-UTR. 


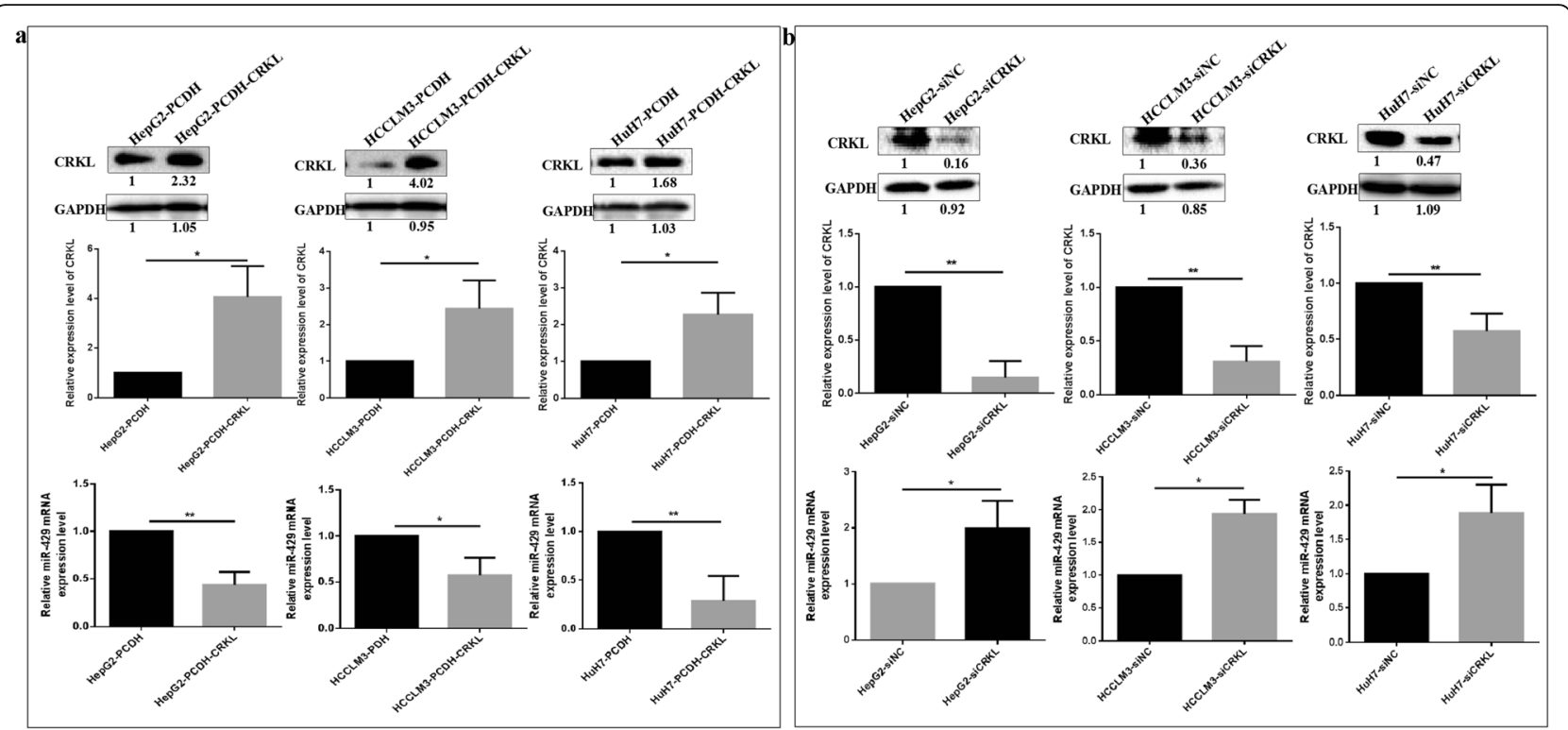

Fig. 9 miR-429 negatively regulates CRKL expression by selectively targeting its 3'-UTR. a CRKL overexpression decreased miR-429 expression levels in HepG2, HCCLM3 and HuH7 cells. b CRKL knockdown increased miR-429 expression levels in HepG2, HCCLM3 and HuH7 cells

\section{Discussion}

The current study has identified a novel ETV6-miR-429CRKL signaling axis that played an important role in HCC, and provided a comprehensive mechanism for the tumorigenesis of HCC in whihc ETV6 binding of miR429 positively regulates CRKL expression. The information gained from this research has important clinical implications for patients with HCC as well as other cancer types associated with elevated ETV6, CRKL expression and decreased miR-429 expression, and may also have clinical impact on other diseases with dysregulated expression of ETV6, CRKL and miR-429. In current work, we only collected 16 pairs of matched tumour tissues and corresponding non-tumor liver tissues from hepatocarcinoma patients, the sample size is relatively small, but our results are reliable, because we also detected the expression patterns and the correlations of ETV6, CRKL and miR-429 in clear cell renal cell carcinoma (ccRCC) patients' tumorous tissues and matched paracancerous nontumoral renal tissues, and bone marrow (BM) of chronic myeloid leukemia (CML) patients and peripheral blood (PB) of normal samples, the expression patterns and the correlations of ETV6, CRKL and miR-429 in cCRCC and CML consistent with those in liver cancer (unpublished). Previously, we have detected the effect of ETV6 on proliferation ability of HCC cells, we found reexpression or silencing of ETV6 slightly affected the proliferation and colony formation abilities of HCCLM3 and $\mathrm{HuH7}$ cells. Meanwhile, re-expression or silencing of miR-429 cannot affect HCC cells proliferation and colony formation abilities, and CRKL only deregulated to a certain degree, which can affect HCC cells proliferation ability [26]. Our results indicated ETV6miR-429-CRKL regulatory circuitry mainly contributed to migration and invasion abilities of HCC cells. So, in current work, we mainly investigated the potential role of ETV6-miR-429-CRKL in metastasis of HCC.

ETV6 is a leukemia-associated gene located on 12p13, which has been shown to play a wide role in hematopoiesis and hematological malignancies [9, 37, 38]. ETV6 frequently forms fusion proteins by chromosomal translocations with partner genes. At present 48 chromosomal bands have been identified to be involved in ETV6 translocations and 30 ETV6 partner genes have been molecularly characterized [11, 39]. Recently, ETV6 has been reported to be involved in solid tumors. ETV6 played an important role in the tumorigenesis of non-small cell lung cancer (NSCLC) and nasopharyngeal carcinoma (NPC) [18, 40], ETV6 overexpresseion in NSCLC tissues and NPC biopsies was correlated with increased patient age and poor prognosis, poor disease-free rates and poor overall survival rates of NSCLC and NPC $[18,40]$. It has been suggested that ETV6 knockdown could inhibit migration and invasion abilities of breast cancer Hs578T cells [41]. However, the role of ETV6 in hepatocarcinoma remains unclear. Our current work showed that the upregulation of ETV6 potentially promoted the clinical development and progression of hepatocarcinoma patients and enhanced hepatocarcinoma cells aggressiveness (Fig. 1a, b). Furthermore, we first investigated the effects of ETV6 deregulation on the malignant behaviors of HCC cells. The overexpression of ETV6 remarkably promoted the in vitro migration and invasion capacities of HCCLM3 and $\mathrm{HuH7}$ cells (Fig. 5c), while, its knockdown significantly inhibited the 
migration and invasion abilities of HCCLM3 and HuH7 cells (Fig. 5d). ETV6 affects cancer cells' malignancy by interrupting cellular F-actin polymerization. ETV6 overexpression resulted in an obvious increase of the F-actin microfilament (Fig. 5e), while, ETV6 knockdown led to an apparent decrease of the F-actin microfilament (Fig. 5e). Our results demonstrated that ETV6 as a tumor promoter in the development and progression of hepatocarcinoma. The movement of cancer cells from one site to another location is a complex process requiring dramatic remodeling of cell cytoskeleton, microfilaments (actin) is major cytoskeletal filaments, tumor cell metastasis as a process of cell motility can be broken down into four steps: protrusion, adhesion, contraction and retraction, abnormal expression or regulation of cytoskeleton components could affect the adhesion with ECM, thus affecting migration and invasion [42-44]. Our results demonstrated that by enhancing the cytoskeleton F-actin polymerization, ETV6 upregulation enhanced the aggressiveness of hepatocarcinoma cells. ETV6 upregulation is a potential indicator for hepatocarcinoma malignancy.

Because of its role as a multi-functional adaptor protein in signal transduction, CRKL deregulation is involved in a variety of cancers. It is an attractive target for the diagnostics, treatment and prognosis of certain cancers [20]. Previously, we detected that endogenous expression level of CRKL in the tumorous tissues from 12 hepatocarcinoma patients was upregulated by $66.7 \%$ compared to the paired non-tumor live tissues [26]. In the current study, the protein level of CRKL was upregulated by $79.6 \%(P=0.0041)$ in the tumor from 16 additional hepatocarcinoma patients (Fig. 2a). IHC results also showed CRKL highly expressed in hepatocarcinoma tissues in over $58.3 \%$ (28 out of 48 ) of the patient samples (Fig. 2c, Table 1). Consistently, CRKL was more abundant in hepatocarcinoma cell lines HepG2, HCCLM3 and $\mathrm{HuH} 7$ compared with normal liver LO2 cells (Fig. 2b). CRKL expression level affected the malignant behaviors of hepatocarcinoma cell lines. Its overexpression promoted the migration (Fig. 6b) and invasion (Fig. 6c) abilities of HepG2, HCCLM3 and HuH7 cells. Consistent with the effect of ETV6 on cytoskeleton, CRKL overexpression led to an increase in the intracellular microfilament of the F-actin cytoskeleton (Fig. 6d). Hence, our current work establishes a tumor promoter role for CRKL in hepatocarcinoma progression and hepatocarcinoma cells aggressiveness.

miR-429 is a member of the miR-200 family including miR-200a, miR-200b, miR-200c, miR-141 and miR-429 [45]. miR-429 abnormal expression is linked to osteosarcoma, renal cancer, ovarian cancer, glioma, breast cancer, oral squamous cell carcinoma, gastric cancer, esophagus cancer, cervical cancer, bladder cancer, lung cancer, prostate cancer, colon cancer [31]. It shows suppression or promotion effects on tumor development, invasion, metastasis, apoptosis and drug-resistance depending on the tumor type and subtype [46-49]. It is a potential indicator for the diagnosis, treatment and prognosis of certain tumors [31, 50-52]. Previously, we detected that the endogenous expression level of miR429 in the tumorous tissues from 12 hepatocarcinoma patients was downregulated compared to the paired non-tumor live tissues [26]. Furthermore, the expression level of miR-429 was downregulated by $27.5 \%(P=$ $0.0136)$ in the tumor from 16 additional hepatocarcinoma patients (Fig. 3a) and in hepatocarcinoma HepG2, HCCLM3 and HuH7 cell lines (Fig. 3b). The deficiency of miR-429 promoted tumorigenesis and malignancy of hepatocarcinoma, and miR-429 played a tumor suppressive role in hepatocarcinoma progression and hepatocarcinoma cells' aggressiveness. The above results were consistent with our previous work showing that miR-429 overexpression or knockdown significantly reduced or increased in vitro migration and invasion capacities of HepG2 cells, respectively [26]. Moreover, miR-429 overexpression resulted in an obvious decrease of F-actin microfilament in HepG2 cells [26]. Also, since the dysexpressions of both ETV6 and CRKL could also affect the malignant behaviors through F-actin polymerization, it is a logical step to connect miR-429 with ETV6 and CRKL in hepatocarcinoma progression.

ETV6 is known to forms fusion protein by chromosomal translocations with ABL [9]. CRKL is a substrate protein for $\mathrm{ABL}$, and the Tel-ABL fusion protein can form complexes with CRKL in leukemia [10]. The HLH domain of ETV6 could mediate dimerization of ABL with subsequent activation of the $\mathrm{ABL}$ kinase domain leading to tyrosine-phosphorylation of CRK, and the Tel-Abl-CRKL complexes activated Ras, MAPK/ERK and AKT/PKB [10]. Consistently, our previous study found miR-429 suppressed migration and invasion by targeting CRKL via inhibiting the Raf/MEK/ERK pathway and EMT [26]. However, whether ETV6 associates with CRKL in solid tumors is unknown. Our work has for the first shown that ETV6 overexpression was positively correlated with CRKL upregulation in hepatocarcinoma tissues and cell lines (Fig. 4a). Moreover, the overexpression and knockdown of CRKL positively upregulated (Fig. 7a) and downregulated (Fig. 7b) ETV6 expression levels in HepG2, HCCLM3 and HuH7 cells. Concordantly, CRKL expression level in these cells could also be positively regulated by ETV6 dysexpression (Fig. 7c). In addition, we have shown that ETV6 directly binds to CRKL by Co-IP assay further indicated the direct interaction between ETV6 and CRKL (Fig. 7d).

The ETV6-NTRK3 (neurotrophic tyrosine kinase receptor type 3) fusion gene was common in cancers such 


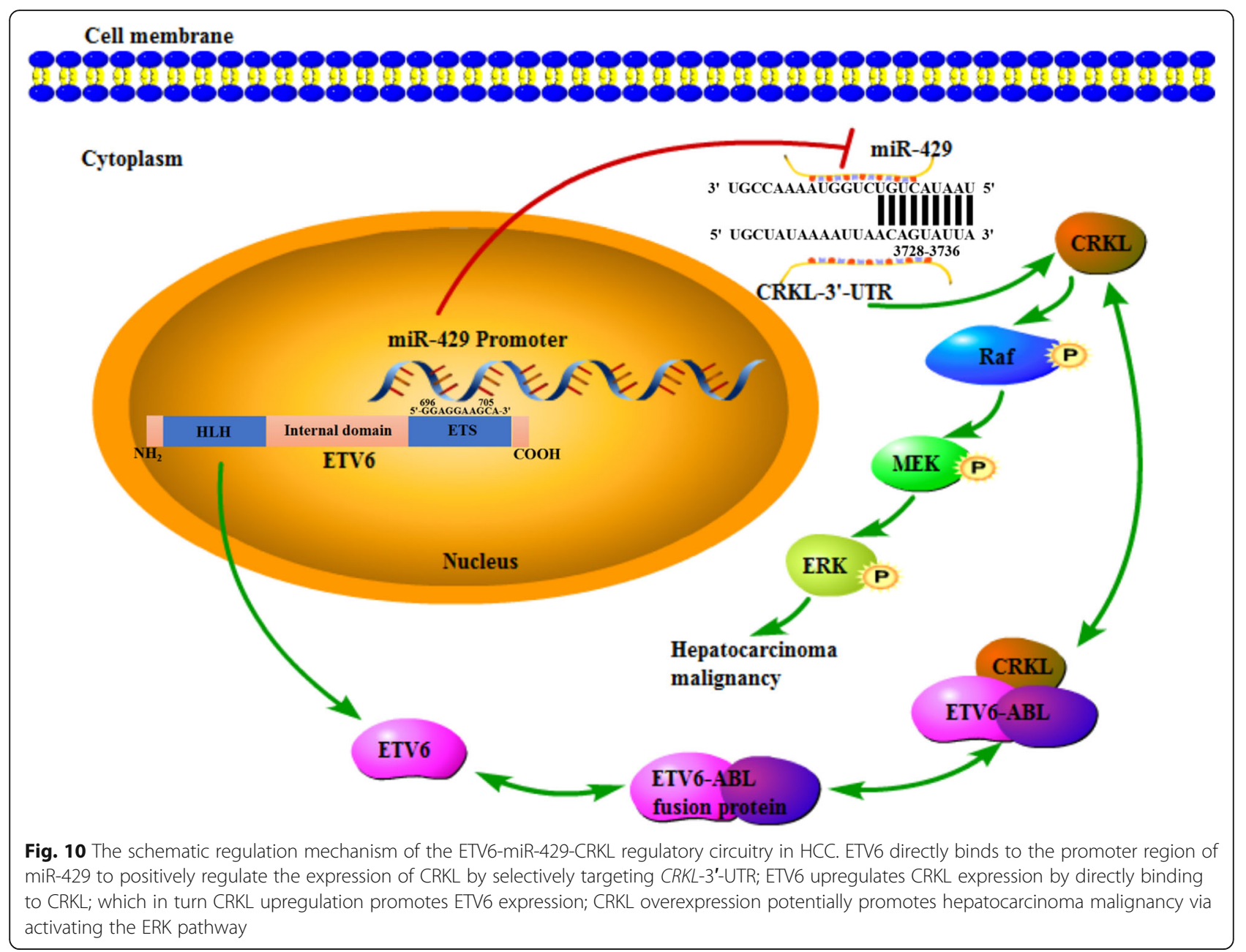

as secretory breast carcinoma, mesoblastic nephroma and congenital fibrosarcoma [53-55], ETV6-NTRK3 fusion oncoprotein could initiate breast cancer from committed mammary progenitors via activation of Wnt (wingless/integrated) signaling pathway [53], committed mammary progenitors, rather than mammary stem cells, are direct targets of transformation, gene fusions with kinase activities has revolutionized targeted therapies for cancer, modeling chromosomal rearrangements in human epithelial tumors could provide novel insights into their pathogenesis, preclinical testing and therapy. The abnormal regulation of Wnt signaling pathway is a major and early carcinogenic event which can be triggered by CTNNB1 (cadherin-associated protein, beta 1), accumulating evidences have demonstrated that activation of Wnt signaling can act in concert with other oncogenes, TGF- $\beta$ (transforming growth factor- $\beta$ ), HGF/c-Met (hepatocyte growth factor/CENP-meta) pathway, HIF-1 $\alpha$ (hypoxia inducing factor 1)/EMT pathway and IGF-1 (insulin-like growth factor 1) pathway, crosstalk between the HGF/cMet pathway and the Wnt pathway might also contribute to the progression of HCC, CTNNB1 enhanced c-Met- stimulated FAK (focal adhesion kinase) activation and synergistically induced the activation of the AKT/ERK pathway [56]. ETV6-CRKL complexes could also activate AKT/ERK pathway. These results demonstrated ETV6 affected tumor progression via AKT/ERK pathway.

The current work also establishes the association of ETV6 with miR-429 in hepatocarcinoma. First, we found that ETV6 upregulation was negatively correlated with miR-429 deficiency in tumorous tissues from hepatocarcinoma patients (Fig. 4c). Second, in comparison with normal liver LO2 cells, a deficiency of miR-429 was measured in hepatocarcinoma cell lines HepG2, HCCLM3 and $\mathrm{HuH7}$ (Fig. 4c). Third, ETV6 negatively regulated miR-429 expression levels in HepG2, HCCLM3 and HuH7 cells (Fig. 8a). ETV6 also acts as a strong transcriptional repressor by directly binding to target genes through an ETS DNA-binding domain to repress its transcription $[11,12]$. The ETS domain is responsible for DNA binding to the ETS-binding consensus site (EBS) that contains a purinerich GGAA/T core motif [50]. Bioinformatics combined with the ChIP assay revealed that by directly binding to the DNA promoter region GGAGGAAGCA at the 696-705 
bp site of miR-429, ETV6 reversely mediated the expression of miR-429 in hepatocarcinoma cells (Fig. 8b).

Previously, we reported that miR-429 negatively regulates CRKL expression in HepG2 cells by selectively targeting its $3^{\prime}$-UTR at the $3728-3735 \mathrm{bp}$ site and we established the primary association of miR-429 with CRKL in hepatocarcinoma [26]. Herein, we demonstrated that the upregulation of CRKL negatively correlated with miR429 deficiency potentially promoted the development and progression of hepatocarcinoma patients and the aggressiveness of hepatocarcinoma cells (Fig. 4b). Meanwhile, we further demonstrated that CRKL negatively regulated miR-429 expression in hepatocarcinoma cell lines. CRKL overexpression and knockdown could decrease (Fig. 9a) and increase (Fig. 9b) the expression levels of miR-429 in HepG2, HCCLM3 and HuH7 cells.

As illustrated in Fig. 10, The ETS domain of ETV6 directly binds to the DNA promoter region GGAGGA AGCA at the 696-705 bp site of miR-429 to suppress its expression, then miR-429 downregulation promotes CRKL expression by selectively targeting CRKL-3'-UTR at the 3728-3735 bp site. Meanwhile, ETV6 forms complexes with CRKL and promotes CRKL expression, which in turn promotes ETV6 expression. Furthermore, CRKL overexpression potentially promotes hepatocarcinoma malignancy by activating ERK pathway.

Hepatocarcinogenesis is a very complex biological process associated with environmental risk factors and hereditary factors, including abnormal activation of Wnt/ $\beta$-catenin, MAPK, AKT, and ERK signaling pathways, and the balance between activation and inactivation of proto-oncogenes and anti-oncogenes, and the differentiation of liver cancer stem cells [57]. Ras/Raf/ ERK is the most crucial pathway in the development and progression of HCC. Signals from membrane-binding tyrosine kinase receptors, such as endothelial growth factor receptor (EGFR), insulin-like growth factor receptor (IGFR), c-Met and PDGFR, are transduced to cell nucleus through Ras/Raf/ERK pathway to regulate multiple cellular functions [57]. Molecule-targeted therapy, a new approach for the treatment of HCC, blocks tumor cells growth by interfering with the molecules required for carcinogenesis. Effective drugs blocking Ras/Raf/ERK signaling are still at exploratory stage, except for sorafenib that has activity inhibiting Raf [57]. Sorafenib is an oral multi-targeted tyrosine kinase inhibitor (TKI) targeting PDGFR, vascular endothelial growth factor (VEGFR), fibroblast growth factor receptor (FGFR), Raf, which is a gold quality standard in the first line treatment of advanced HCC patients. Cancer biomarkers have been widely used for prediction of prognosis and treatment response in certain tumors $[58,59]$. Predictive biomarkers can be best explored in the setting of properly designed clinical trials, and it is important to develop biomarkers to narrow down the subgroup of the patients who have a survival benefit from sorafenib treatment.

Our results showed that an ETV6-miR-429-CRKL regulatory circuitry contributes to aggressiveness of HCC by activating Ras/Raf/ERK pathway. ETV6 is known to forms fusion protein with PDGFR, CRKL can function in cellular signaling cascades by directly forms complex with downstream receptor protein to regulate cellular tyrosine kinase activity, meanwhile, some miRNAs have been evaluated for the prediction of response to sorafenib treatment in HCC [60]. While, sorafenib as a TKI could directly inhibit PDGFR and Raf, we speculate ETV6, CRKL, miR-429 might as novel biomarkers for the predication of sorafenib response in HCC, in the future study, we will clarified and validated whether ETV6, CRKL, miR-429 could predict the response of $\mathrm{HCC}$ to sorafenib treatment, and we expect ETV6, CRKL, miR-429 could help identify the subclass of HCC patients who would likely respond to sorafenib treatment. Molecule-targeted therapy will gradually become a new favorite for treatment of HCC, and also represent the future developmental direction of treatment of HCC. Furthermore, fundamental research breakthroughs will create more effective methods for $\mathrm{HCC}$ targeted therapy.

\section{Conclusions}

CRKL, ETV6 acts as tumor promotors and miR-429 acts as a tumor suppressor in $\mathrm{HCC}$, their dysexpressions are involved in the carcinogenesis and progression of hepatocarcinoma. We have uncovered a novel ETV6miR-429-CRKL regulatory circuitry that contributes to hepatocarcinoma tumorigenesis. The newly identified ETV6-miR-429-CRKL regulatory circuitry from the current work provides new insights into the underlying mechanism of pathogenesis in HCC and represents a potential therapeutic target for diagnosis and treatment of HCC.

\section{Supplementary information}

Supplementary information accompanies this paper at https://doi.org/10. 1186/s13046-020-01559-1.

\section{Additional file 1.}

\section{Abbreviations}

HCC: Human hepatocellular carcinoma; CRKL: V-crk sarcoma virus oncogene homologue (avian)-like; ECM: Extracellular matrix; HLH: Helix-loop-helix; PNT: Pointed domain; SAM: Sterile alpha motif domain; ETS: E-Twenty Six; ETV6: ETS variant gene 6; Tel: Translocation ets leukaemia; EBS: ETS-binding consensus site; PDGFR: Platelet-derived growth factor receptor; ABL: V-abl Abelson murine leukemia viral oncogene; EVI-1: Ecotropic virus integration site 1; RUXN1: Runt-related transcription factor 1 gene; Ras: Rat sarcoma; MAPK/ERK: Mitogen-activated protein kinase/extracellular regulated protein kinases; PKB/AKT: Protein kinase B/Serine/threonine kinase; BCAR1: Breast cancer anti-estrogen resistance 1; GAB: Grb2-associated binder protein; Pax: Paired boxed gene; GEF: Guanine nucleotide exchange factor; C3G: 3domain-binding guanine nucleotide exchange factor; BCR: B-cell receptor; 
SOS: Son of sevenless; Raf: Rapidly accelerated fibrosarcoma; MEK: Mitogenactivated extracellular signal-regulated kinase; miRNAs: MicroRNAs; 3'-UTR: 3'untranslated region; EMT: Epithelial-mesenchymal transition; HBV: Hepatitis B virus; AFP: Alpha fetoprotein; DMEM: Dulbecco's modified Eagle's medium; FBS: Fetal bovine serum; WB: Western blotting; RT: Room temperature; NC: Nitrocellulose; ACTB: $\beta$-actin; GAPDH: Glyceraldehyde-3-phosphate dehydrogenase; HRP: Horseradish peroxidase; PBS: Phosphate buffered solution; IHC: Immunohistochemistry; qRT-PCR: Quantitative real-time PCR: TRITC: Tetramethyl rhodamin isothiocyanate; RIPA: Radioimmunoprecipitation assay; SDS-PAGE: Sodium dodecyl sulfatepolyacrylamide gel electrophoresis; TBST: Tris-buffered-saline-tween 20; PMSF: Phenylmethanesulfonyl fluoride; BSA: Bovine serum albumin; ECL: Electrochemiluminescence; DAB: Diaminobenzidin; siRNA: Small interfering RNA; Co-IP: Co-immunoprecipitation; ChIP: Chromatin immunoprecipitation; NSCLC: Non-small cell lung cancer; NPC: Nasopharyngeal carcinoma; SH2: Src homology2; SH3N: N-terminal SH3; SH3C: C-terminal SH3; ccRCC: Clear cell renal cell carcinoma; BM: Bone marrow; CML: Chronic myeloid leukemia; PB: Peripheral blood; NTRK3: Neurotrophic tyrosine kinase receptor type 3; Wnt: Wingless/ Integrated; CTNNB1: Cadherin-associated protein, beta 1; TGF$\beta$ : Ttransforming growth factor- $\beta$; HGF/c-Met: Hepatocyte growth factor/ CENP-meta; HIF-1a: Hypoxia inducing factor 1; IGF-1: Insulin-like growth factor 1; FAK: Focal adhesion kinase; EGFR: Growth factor receptor; IGFR: Insulin-like growth factor receptor; TKI: Tyrosine kinase inhibitor; VEGFR: Vascular endothelial growth factor; FGFR: Fbroblast growth factor receptor

\section{Acknowledgements}

Not applicable.

\section{Authors' contributions}

CMG, SQL and MZS conceived the study and designed the experiments; CMG, CG and DTZ performed in vitro experiments; JHL and XJS performed immunohistochemical staining; JXW and QLL organized the clinical samples; LHH and YXT analyzed the data; CMG, and CG wrote the manuscript; SQL, MZS and FTG modified the manuscript. All authors read and approved the final manuscript.

\section{Funding}

This work was supported by grants from the National Natural Science Foundation of China (81672737, 81272186, 31900517), the Natural Science Foundation of Liaoning (LZ2019003, 20181550168, LQ2017001).

\section{Availability of data and materials}

The data supporting the conclusions of this article are included within the article.

\section{Ethics approval and consent to participate}

This study has been conducted in accordance with ethical standards and according to the Declaration of Helsinki and the national and international guidelines, and has been approved by the authors' institutional review board. The study protocol was approved by the Medical Ethics Committee of Dalian Medical University.

\section{Consent for publication}

Not applicable.

\section{Competing interests}

The authors declare that they have no competing interests.

\section{Author details}

${ }^{1}$ Department of Biotechnology, College of Basic Medical Sciences, Dalian Medical University, Dalian 116044, China. ${ }^{2}$ Department of Biochemistry, College of Basic Medical Sciences, Dalian Medical University, Dalian 116044, China. ${ }^{3}$ Department of General Surgery, The Second Affiliated Hospital, Dalian Medical University, Dalian 116044, China. ${ }^{4}$ Department of Histology and Embryology, College of Basic Medical Sciences, Dalian Medical University, Dalian 116044, China. ${ }^{5}$ Carlson School of Chemistry and Biochemistry, Clark University, Worcester, MA 01610, USA.
Received: 31 December 2019 Accepted: 10 March 2020

Published online: 23 April 2020

\section{References}

1. Siege RL, Miller KD, Jemal A. Cancer statistics. Cancer J Clin. 2019;69(1):7-34.

2. El-Serag HB. Epidemiology of viral hepatitis and hepatocellular carcinoma. Gastroenterology. 2012;142(6):1261-72.

3. Sun XJ, Liu SQ, Wang JX, Wei B, Guo CM, Chen C, et al. Annexin A5 regulates hepatocarcinoma malignancy via CRKI/II-DOCK180-RAC1 integrin and MEK-ERK pathways. Cell Death Dis. 2018;9:637.

4. Klungboonkrong $\mathrm{V}$, Das D, Mclennan G. Molecular mechanisms and targets of therapy for hepatocellular carcinoma. J Vasc Interv Radiol. 2017;28(7):949-55.

5. Setshedi M, Andersson M, Kgatle MM, Roberts L. Molecular and cellular oncogenic mechanisms in hepatocellular carcinoma. S Afr Med J. 2018; 108(8b):41-6.

6. Hock H, Shimamura A. ETV6 in hematopoiesis and leukemia predisposition. Semin Hematol. 2017;54(2):98-104.

7. De S, Chan AC, Coyne HJ, Bhachech N, Hermsdorf U, Okon M, et al. Steric mechanism of auto-inhibitory regulation of specific and non-specific DNA binding by the ETS transcriptional repressor ETV6. J Mol Biol. 2014;426(7): 1390-406.

8. Zaliova M, Moorman AV, Cazzaniga G, Stanulla M, Harvey RC, Roberts KG, et al. Characterization of leukemias with ETV6-ABL1 fusion. Haematologica. 2016;101(9):1082-93.

9. De Braekeleer E, Douet-Guilbert N, Morel F, Le Bris MJ, Basinko A, De Braekeleer M. ETV6 fusion genes in hematological malignancies: a review. Leuk Res. 2012;36(8):945-61.

10. Voss J, Posern G, Hannemann JR, Wiedemann LM, Turhan AG, Poirel H, et al. The leukaemic oncoproteins Bcr-Abl and Tel-Abl (ETV6/Abl) have altered substrate preferences and activate similar intracellular signalling pathways. Oncogene. 2000;19(13):1684-90.

11. Lopez RG, Carron C, Oury C, Gardellin P, Bernard O, Ghysdael J. TEL is a sequence-specific transcriptional repressor. J Biol Chem. 1999;274(42):30132-8.

12. Green SM, Coyne HJ, McIntosh LP, Graves BJ. DNA binding by the ETS protein TEL (ETV6) is regulated by autoinhibition and self-association. J Biol Chem. 2010;285(24):18496-504.

13. Rasighaemi P, Liongue C, Onnebo SM, Ward AC. Functional analysis of truncated forms of ETV6. Br J Haematol. 2015;171(4):658-62.

14. Rasighaemi P, Onnebo SMN, Liongue C, Ward AC. ETV6 (TEL1) regulates embryonic hematopoiesis in zebrafish. Haematologica. 2015;100(1):23-31.

15. Moriyama T, Metzger ML, Wu G, Nishii R, Qian M, Devidas M, et al. Germline genetic variation in ETV6 and risk of childhood acute lymphoblastic leukemia: a systematic genetic study. Lancet Oncol. 2015;16(16):1659-66.

16. Noetzli L, Lo RW, Lee-Sherick AB, Callaghan M, Noris P, Savoia A, et al. Germline mutations in ETV6 are associated with thrombocytopenia, red cell macrocytosis and predisposition to lymphoblastic leukemia. Nat Genet. 2015;47(5):535-58.

17. Wang M, Gu D, Du M, Xu Z, Zhang S, Zhu L, et al. Common genetic variation in ETV6 is associated with colorectal cancer susceptibility. Nat Commun. 2016;7:11478.

18. Ke L, Zhou H, Wang C, Xiong G, Xiang Y, Ling Y, et al. Nasopharyngeal carcinoma super-enhancer-driven ETV6 correlates with prognosis. Proc Natl Acad Sci U S A. 2017;114(36):9683-8.

19. Birge RB, Kalodimos C, Inagaki F, Tanaka S. Crk and CRKL adaptor proteins: networks for physiological and pathological signaling. Cell Commun Signal. 2009;7(1):13.

20. Guo CM, Liu SQ, Sun M-Z. The role of CT10 regulation of kinase-like in cancer. Future Oncol. 2014;10(16):2687-97.

21. Lin QY, Sun M-Z, Guo CM, Shi J, Chen X, Liu SQ. CRKL overexpression suppresses in vitro proliferation, invasion and migration of murine hepatocarcinoma Hca-P cells. Biomed Pharmacother. 2015;69:11-7.

22. Park T, Koptyra M, Curran T. Fibroblast growth requires CT10 regulator of kinase (Crk) and Crk-like (CrkL). J Biol Chem. 2016;291(51):26273-90.

23. Emily SB, Morag P. Models of Crk adaptor proteins in cancer. Genes Cancer. 2012;3(5-6):341-52.

24. Sriram G, Birge RB. Emerging roles for crk in human cancer. Genes Cancer. 2010;1(11):1132-9.

25. Shi J, Meng LL, Sun M-Z, Guo CM, Sun XJ, Lin QY, et al. CRKL knockdown promotes in vitro proliferation, migration and invasion, in vivo tumor malignancy and lymph node metastasis of murine hepatocarcinoma Hca-P cells. Biomed Pharmacother. 2015;71(1):84-90. 
26. Guo CM, Zhao DT, Zhang QL, Liu SQ, Sun M-Z. miR-429 suppresses tumor migration and invasion by targeting CRKL in hepatocellular carcinoma via inhibiting Raf/MEK/ERK. Sci Rep. 2018;8(1):2375

27. Fang YX, Gao WG. Roles of microRNAs during prostatic tumorigenesis and tumor progression. Oncogene. 2014;33(2):135-47.

28. Calin GA, Croce CM. MicroRNA signatures in human cancers. Nat Rev Cancer. 2006;6(11):857-66.

29. Volinia S, Calin GA, Liu CG, Ambs S, Cimmino A. A microRNA expression signature of human solid tumors defines cancer gene targets. PNAS. 2006; 103:2257-61.

30. Zimmerman AL, Wu S. MicroRNAs, cancer and cancer stem cells. Cancer Lett. 2011;300(1):10-9.

31. Liu X, Zhang J, Xie B, Li H, Shen J, Chen J. MicroRNA-200 family profle: a promising ancillary tool for accurate cancer diagnosis. Am J Ter. 2016;23(2): e388-97.

32. Ye ZB, Ma G, Zhao YH, Xiao Y, Zhang Y, Jing C, et al. miR-429 inhibits migration and invasion of breast cancer cells in vitro. Int J Oncol. 2016;46: 531-8.

33. Tang J, Li L, Huang W, Sui C, Yang Y, Lin X, et al. MiR-429 increases the metastatic capability of HCC via regulating classic Wnt pathway rather than epithelial-mesenchymal transition. Cancer Lett. 2015;364(1):33-43.

34. Li D, Wang H, Song H, Xu H, Zhao B, Wu C, et al. The microRNAs miR-200b$3 p$ and miR-429-5p target the LIMK1/CFL1 pathway to inhibit growth and motility of breast cancer cells. Oncotarget. 2017;8(49):85276-89.

35. Han Y, Zhao Q, Zhou J, Shi R. miR-429 mediates tumor growth and metastasis in colorectal cancer. Am J Cancer Res. 2017;7(2):218-33.

36. Zou J, Liu L, Wang Q, Yin F, Yang Z, Zhang W, et al. Downregulation of miR429 contributes to the development of drug resistance in epithelial ovarian cancer by targeting ZEB1. Am J Transl Res. 2017;9(3):1357-68.

37. Bohlander SK. ETV6: a versatile player in leukemogenesis. Semin Cancer Biol. 2005;15(3):162-74.

38. Chakrabarti SR, Nucifora G. The leukemia-associated gene TEL encodes a transcription repressor which associates with SMRT and mSin3A. Biochem Biophys Res Commun. 1999;264(3):871-7.

39. Sakurai T, Yamada T, Kihara-Negishi F, Teramoto S, Sato Y, Izawa T, et al. Effects of overexpression of the Ets family transcription factor TEL on cel growth and differentiation of K562 cells. Int J Oncol. 2003;22(6):1327-33.

40. Liang JZ, Li YH, Zhang Y, Wu QN, Wu QL. Expression of ETV6/TEL is associated with prognosis in non-small cell lung cancer. Int J Clin Exp Pathol. 2015;8(3):2937-45.

41. Hong $L$, Pan F, Jiang $H$, Zhang $L$, Liu $Y$, Jiang $C$, et al. miR-125b regulates invasion and migration by targeting ETV6 in Hs578T breast cancer cells. Chin J Gene Prac. 2017;15(8):1326-30.

42. Small JV, Stradal T, Vignal E, Rottner K. The lamellipodium: where motility begins. Trends Cell Biol. 2002;12(3):112-20.

43. Pollard TD, Borisy GG. Cellular motility driven by assembly and disassembly of actin filaments. Cell. 2003;112(4):453-65.

44. Ridley AJ, Schwartz MA, Burridge K, Firtel RA, Ginsberg MH, Borisy G. Cell migration: integrating signals from front to back. Science. 2003;302(5651): 1704-9.

45. Feng B, Wang R, Chen LB. Review of miR-200b and cancer chemosensitivity. Biomed Pharmacother. 2012;66:397-402.

46. Hu X, Macdonald DM, Huettner PC, Feng Z, El Naqa IM, Schwarz JK, et al. A miR-200 microRNA cluster as prognostic marker in advanced ovarian cancer. Gynecol Oncol. 2009;114(3):457-64.

47. Qiu M, Liang Z, Chen L, Tan G, Wang K, Liu L, et al. MicroRNA-429 suppresses cell proliferation, epithelial-mesenchymal transition, and metastasis by direct targeting of BMI1 and E2F3 in renal cell carcinoma. Urol Oncol. 2015;33(7):332 (e9-e18).

48. Wu D, Niu X, Pan H, Zhou Y, Zhang Z, Qu P, et al. Tumor-suppressing effects of microRNA-429 in human renal cell carcinoma via the downregulation of Sp1. Oncol Lett. 2016;12(4):2906-11.

49. Wang C, Ju H, Shen C, Tong Z. miR-429 mediates delta-tocotrienol-induced apoptosis in triple-negative breast cancer cells by targeting XIAP. Int J Clin Exp Med. 2015;8(9):15648-56.

50. Xiao P, Liu W, Zhou H. miR-429 promotes the proliferation of non-small cell lung cancer cells via targeting DLC-1. Oncol Lett. 2016;12(3):2163-8.

51. Sun $Y$, Shen S, Tang H, Xiang J, Peng Y, Tang A, et al. miR-429 identified by dynamic transcriptome analysis is a new candidate biomarker for colorectal cancer prognosis. OMICS. 2014;18(1):54-64.
52. Guo CM, Liu SQ, Sun M-Z. miR-429 as biomarker for diagnosis, treatment and prognosis of cancers and its potential action mechanisms: a systematic literature review. Neoplasma:190401N282. 2019. In Press.

53. Li Z, Tognon CE, Godinho FJ, Yasaitis L, Hock H, Herschkowitz Jl, et al. ETV6NTRK3 fusion oncogene initiates breast cancer from committed mammary progenitors via activation of AP1 complex. Cancer Cell. 2007;12(6):542-58.

54. Euhus DM, Timmons CF, Tomlinson GE. ETV6-NTRK3-Trk-ing the primary event in human secretory breast cancer. Cancer Cell. 2002;2(5):347-8.

55. Knezevich SR, Garnett MJ, Pysher TJ, Beckwith JB, Grundy PE, Sorensen PH. ETV6-NTRK3 gene fusions and trisomy 11 establish a histogenetic link between mesoblastic nephroma and congenital fibrosarcoma. Cancer Res. 1998;58(22):5046-8.

56. Liu LJ, Xie SX, Chen YT, Xue JL, Zhang CJ, Zhu F. Aberrant regulation of Wnt signaling in hepatocellular carcinoma. World J Gastroenterol. 2016;22(33): 7486-99.

57. Chen C, Wang G. Mechanisms of hepatocellular carcinoma and challenges and opportunities for molecular targeted therapy. World J Hepatol. 2015; 7(15):1964-70

58. Brunetti O, Gnoni A, Licchetta A, Longo V, Calabrese A, Argentiero A, et al. Predictive and prognostic factors in HCC patients treated with sorafenib. Medicina. 2019;55(10):707.

59. Llovet JM, Ricci S, Mazzaferro V, Hilgard P, Gane E, Blanc JF, et al. Sorafenib in advanced hepatocellular carcinoma. N Engl J Med. 2008;359(4):378-90.

60. Nishida N, Arizumi T, Hagiwara S, Ida H, Sakurai T, Kudo M. MicroRNAs for the prediction of early response to sorafenib treatment in human hepatocellular carcinoma. Liver Cancer. 2017;6(2):113-25.

\section{Publisher's Note}

Springer Nature remains neutral with regard to jurisdictional claims in published maps and institutional affiliations.

Ready to submit your research? Choose BMC and benefit from

- fast, convenient online submission

- thorough peer review by experienced researchers in your field

- rapid publication on acceptance

- support for research data, including large and complex data types

- gold Open Access which fosters wider collaboration and increased citations

- maximum visibility for your research: over $100 \mathrm{M}$ website views per year

At BMC, research is always in progress.

Learn more biomedcentral.com/submissions 